\title{
Intensification Mechanisms Driving Dietary Change among the Great Plains Big Game Hunters of North America
}

\author{
*Erik Otárola-Castillo ${ }^{1}$, Melissa G. Torquato ${ }^{1}$, and *Matthew E. Hill ${ }^{2}$ \\ ${ }^{1}$ Department of Anthropology, Purdue University, West Lafayette, IN, USA, email: \\ eoc@purdue.edu \\ ${ }^{2}$ Department of Anthropology, University of Iowa, Iowa City, IA, USA, email: matthew-e- \\ hill@uiowa.edu
}

*Corresponding Authors

11,220 words, 4 tables, 8 figures 


\section{INTRODUCTION}

2 Studies of dietary diversity are prominent in the zooarchaeological literature and have been

3 pivotal to understanding prehistoric economies. Investigations of diachronic changes in

4 economic strategies have focused on a broad selection of topics, including human-environment

5 interactions, ecological adaptations, the origins of farming, human-caused extinctions and animal

6 translocation, and the development of social complexity (e.g., Boivin, et al. 2016; Broughton

7 1999, 2002; DeAngelis and Lyman 2018; Munro, et al. 2018; Nagaoka 2002; Stiner and Munro

8 2002; Weitzel 2019). Such studies often attempt to understand the factors contributing to

9 changes in dietary diversity, focusing on the idea of resource intensification, or Boserup’s

10 Theory, which is commonly defined as the ability of human populations to obtain more food in a

11 given unit of time, labor, or space (Binford 2001 :357; Boserup 1965; Broughton 1994b).

12 Boserup posited that when humans intensify food production, they incur a decline in

13 productive efficiency, as increasing the food yield involves a disproportionate increase in costs

14 relative to gains. Anthropologists have vigorously debated Boserup's Theory and the definition

15 of intensification (Betts and Friesen 2004; Earle 1980; Matson 1983; Morrison 1994). Some have

16 argued that intensification can occur even without a decline in efficiency (e.g., Brookfield 1972;

17 Leach 1999; Morgan 2015; Morrison 1994). Others have focused on understanding what they

18 call the "component strategies" of resource intensification, or what we term the "mechanisms" of

19 intensification: specialization, diversification, and investment (Betts and Friesen 2004; Morrison

20 1994). In zooarchaeology, specialization refers to economic strategies through which hunters

21 focus on procuring a narrow range of species, typically with an associated decline in the

22 procurement of other species; (Lyman 1989, 1991). Diversification, meanwhile, is a strategy 
1 through which hunters rely on a broader range of food species or change the organization of the

2 types of species procured.

3 Archaeologists have observed material culture representing both diversified and specialized

4 economies across the North American Great Plains and its adjacent regions. Economic systems

5 in this region have a record of at least 13,000 years of variation, likely due, at least partially, to

6 diachronic (temporal) and synchronic (regional) variability in environmental conditions, and

7 human and prey population pressures. Despite this variation, an apparent big-game hunting

8 specialization seems to have persisted in this region alongside more diversified strategies,

9 including a broad spectrum of small-to-medium-sized prey (Kelly and Todd 1988). This hunting-

10 focused specialization lasted much longer than it did in many other regions of North America,

11 where domesticates were adopted earlier (Fagan 2018; Neusius and Gross 2013). Early Great

12 Plains archaeologists have proposed a simplified progression of subsistence intensification

13 through time, starting with specialized big-game hunters in the Paleoindian period (13,500-9,000

14 BP) to the Late Prehistoric period (1000-300 BP), which was then characterized by a diversified

15 economy that included gathered, hunted, and domesticated resources (e.g., Lehmer 1971 :30-33;

16 Liberty and Wood 1980 :37-41; Wedel 1940; 1953 :509).

17 Although recent research has presented much more nuanced inferences regarding the

18 subsistence economies of peoples on the Great Plains, the apparent trend toward resource

19 intensification has remained a clear pattern. For example, researchers have begun to question the

20 traditional view of Paleoindians as big prey hunting specialists (Blackmar and Hofman 2006;

21 DeAngelis and Lyman 2018; Hill 2007a, 2008; Kornfeld and Larson 2008; Kornfeld, et al.

22 2007). Studies of later periods on the Plains have acknowledged a broader range of regional

23 variability in subsistence practices, including an increasing diversity of hunted and gathered 
1 foods. Researchers have also documented the appearance and intensification of domesticated

2 resources during the Woodland and Late Prehistoric periods (e.g., Adair and Drass 2011; Bozell,

3 et al. 2011). Investigating the economic variability observed across this vast region has great

4 potential to shed light on the broad range of behaviors and technologies driving the

5 intensification mechanisms used by human populations to produce food.

6 Consequently, this study investigates the broad patterns of change in the economic strategies

7 used by Great Plains indigenous communities in order to evaluate the hypothesis that prehistoric

8 small-scale societies of the Great Plains increasingly and unidirectionally intensified their

9 resource base over time. We examine the hunting and gathering economies of the Paleoindian

10 period through to the farming societies of the Late Prehistoric period to compare how

11 populations approached the intensification of a nearly identical suite of faunal resources. We

12 focus on the long-term use of intensification mechanisms within major habitat settings of the

13 Great Plains and the Rocky Mountains, including alluvial valleys, foothills and mountains, and

14 plains and rolling hills (Hill 2008; Knell and Hill 2012).

15 To evaluate this hypothesis and track subsistence shifts through time, we use faunal evidence

16 of more than 200 zooarchaeological assemblages from across the North American Great Plains

17 and adjacent regions, dating from the last 13,500 years. We assess the variability of dietary

18 diversity via species richness and evenness, including the relative ratios of different sized prey,

19 across the geographical extent of the Great Plains through time. In doing so, this study yields a

20 better understanding of the long-term trends in the intensification of the human use of animals in

21 this region.

22 Before describing the methods and results of this study, we provide a summary of prior

23 zooarchaeological approaches to the study of animal resource intensification. In part, we discuss 
1 how our preceding work on Paleoindian subsistence has laid the foundation for a comparative

2 study of later periods. The large temporal scale of our study provides a more comprehensive

3 understanding of the economic strategies of Great Plains prehistoric foragers and farmers within

4 the changing paleoenvironmental conditions in which these groups lived.

5

6

7

8 population dynamics of small-scale farming societies. Boserup argued that, from a Malthusian

9 perspective, small-scale farmers had little control over their population growth, which was

10 instead controlled by the food supply available to these "primitive" farmers. In effect, the

11 Malthusians viewed historical changes in human population sizes as the product of technological

12 developments that generated increases in food productivity. For Boserup, however, the notion of

13 food production as the ultimate limiting factor of population growth did not capture the reality of

14 ancient and contemporary small-scale populations. Instead, this idea likely reflected

15 contemporaneous Western European agricultural practices, which were characterized by

16 extensive expansion to create new cultivation fields. By contrast, Boserup argued that human

17 population growth was the driving force for increasing food productivity via intensive rather than

18 extensive food production.

19 Over the past 50 years, archaeologists have elaborated many definitions of resource

20 intensification, often depending on the focus of the research, i.e., whether it is on agricultural or

21 hunter-gatherer societies (Moss 2012; Thurston and Fisher 2007). Zooarchaeologists have argued

22 that the increase in foraging productivity via intensification arises through the mechanisms of

23 specialization, diversification, and investment (Butler and Campbell 2004; Moss 2012). 
1 Diversification and specialization subsistence strategies are complex. Although one could

2 assume that for past societies these strategies would be mutually exclusive, (Betts and Friesen

3 2004: 359) argue that this is an incorrect assumption. In fact, when considered over a long period

4 of time, specialization and diversification may emerge as complementary strategies. Investment

5 in new technologies or behaviors is often directly tied to strategies of specialization and

6 diversification (Binford 1980; 2001 :189). Yet, as Earle (1980) notes, increased investments and

7 specialization may contribute to resource intensification only up to a point; only diversification

8 will allow for further intensification. Below, we use these mechanisms to structure a summary of

9 how recent zooarchaeologists have identified and used the concept of faunal resource

10 intensification (Betts and Friesen 2004; Morrison 1994).

11 Especially in non-agricultural societies, archaeologists have often viewed specialization as a

12 path to increased efficiency. In their discussion of the adaptations of the peopling of the

13 Americas, Kelly and Todd (1988) hypothesized that a high-technology, highly specialized big-

14 prey hunting strategy might have enabled early foragers to move through the new landscape,

15 regardless of the environmental setting or seasonality. Recent research has inferred that early

16 hunters in North America were indeed big-game hunting specialists (e.g., Surovell and

17 Waguespack 2008, 2009); however, the hunting specialization hypothesis might be too simplistic

18 to capture the variability of these foragers' hunting behaviors (e.g., Cannon and Meltzer 2008;

19 DeAngelis and Lyman 2018; Haynes and Hutson 2014; Hill 2007a, 2008). In addition, in studies

20 of Paleoindian foraging and prey use in the Great Plains and Rocky Mountains, Hill (2007a,

21 2007b, 2008; Hill and Knell 2013; Knell and Hill 2012) and Otárola-Castillo (2016) have found

22 statistically meaningful differences in prey use across habitats, potentially by the same hunting

23 groups. For example, in the High Plains grasslands, there was low temporal and spatial 
1 predictability of important game and other biotic and non-biotic resources. This habitat likely

2 provided a selective advantage for Paleoindian hunters to approach prey choice with a more

3 specialist stance. At the same time, the same hunter may have found it better to practice a more

4 generalist diet in an alluvial valley habitat, where resources were more predictable. These

5 findings highlight the flexibility with which these early foraging groups behaved.

6 Researchers studying North America during later periods have also observed specialization

7 among hunter-gatherers. In the Northern Plains, for example, researchers have proposed that

8 Middle Holocene ( $\sim 5500-5500$ years ago) foragers were specialized bison hunters, perhaps in

9 response to the paucity of alternative plant or animal resources in the region (Forbis 1982; Frison

10 1998a; Robertson 2011). Research from the Pacific Northwest has suggested a causal link

11 between the economic surplus arising from fishing specialization and the region's increasing

12 social complexity over the last 3500 years (e.g., Butler and Campbell 2004; Coupland, et al.

13 2010; Fladmark 1975; Matson and Coupland 1995; Moss 2012).

14 Studies on the origins of herding and farming have frequently used Boserup’s Theory to

15 explain that domestication was rooted in a decline in foraging efficiency (Weitzel 2019).

16 However, there has been disagreement about whether declines in foraging efficiencies were due

17 to population increases (i.e., demographic packing; Broughton 1994b; Munro 2004; Munro, et al.

18 2018; 2000; Stiner, et al. 1999) or environmental change (Gremillion and Piperno 2009). Most

19 researchers who have examined the rise of farming in connection with foraging declines have

20 inferred that the mechanism of resource intensification was diversification (Munro 2009; Zeder

21 2012) as members of hunting and gathering economies adopted new strategies or technologies to

22 exploit previously unrealized parts of their dietary niche. However, in this case, the increased 
1 cost of the behavioral or technological investment would have decreased the overall dietary

2 efficiency (e.g., Bettinger, et al. 2006; Munro 2009; Ugan, et al. 2003).

3 Flannery (1968) famously coined the term Broad Spectrum Revolution (BSR) to describe the

4 dietary diversification strategy adopted by foraging societies, which led to the emergence of

5 Neolithic farmer societies as part of a long-term trend of resource intensification caused by

6 increasing population pressures (see review in Zeder 2012). To investigate the hypotheses of the

7 BSR, researchers have increasingly employed Optimal Foraging Theory (OFT) as a quantitative

8 hypothesis testing framework (Broughton, et al. 2010; Byers and Broughton 2004; Gremillion

9 2004; Gremillion, et al. 2014; Winterhalder 1986) however, see a critique of OFT for studying

10 the origins of domestication in (Smith 2011, 2015; Zeder 2012, 2015, 2016). Classic OFT

11 heuristics like the diet breadth model (DBM), also known as the prey model or prey choice

12 model, predict when and how foragers will diversify their diet base. These models assume that

13 foragers rank all prey according to their rate of energy acquisition over the time spent foraging

14 (E/T) and that they tend to maximize this ratio. The DBM suggests that when high-ranked prey

15 become scarcer, foragers should diversify their diet by including low E/T ranked prey.

16 In this context, OFT and the DBM have been successful at generating testable hypotheses

17 regarding foraging and farming populations (Bettinger and Grote 2016; Bird and O’Connell

18 2006). However, Stiner and colleagues (Stiner 2001; Stiner and Munro 2002; Stiner, et al. 2000;

19 Stiner, et al. 1999; Zeder 2012) have challenged Flannery’s original conceptualization of the

20 BSR in the Mediterranean Basin based on their application of foraging theory. Rather than

21 following traditional Linnaean taxonomic categories, Stiner and colleagues used alternative

22 classifications as the basis for measuring the change in dietary diversity. They argued that there

23 were clear archaeological signals for the BSR when focusing on the practical differences 
1 between prey, for example, the prey handling costs (e.g., pursuit, capture, and processing)

2 associated with pursuing small vs. large prey. Results of Stiner and colleagues' work showed that

3 Mediterranean societies during the Late Pleistocene shifted away from slow-moving prey, such

4 as tortoises and shellfish, and increasingly began including fast-moving prey, such as birds,

5 hares, and rabbits, in their diet. The researchers attributed these changes in prey use to

6 demographically driven resource pressures.

7 In North America, there have been numerous applications of OFT principles in order to 8 understand the subsistence strategies of hunter-gatherer and farming populations (Bettinger and

9 Grote 2016; Bird and O’Connell 2006). For example, Barlow (2002) argued that increases in

10 maize agriculture in the Great Basin were likely due to long-term decreases in wild prey and

11 plant resources. Broughton $(1997,1999)$ showed that occupants of the Emeryville Shell mound

12 in San Francisco Bay broadened their diet breadth by including low-ranked prey such as marine

13 mammals, mollusks, small fish, and acorns. Broughton proposed that this type of resource

14 intensification was a response to declines in high-ranked prey such as elk, deer, and large fish.

15 Likewise, the McElmo Dome area of Mesa Verde, in southwestern Colorado, provides an

16 example of macro-nutrient intensification. In this study, Ellyson et al. (2019) used predictions

17 from OFT to contextualize their analysis of faunal remains left by farmer-gatherer-hunters who

18 occupied the area during AD 900-1280. The subsistence system at Mesa Verde depended on

19 both hunting and husbandry practices. However, when the availability of hunted prey declined,

20 the people at Mesa Verde intensified turkey husbandry practices, likely in order to maintain

21 appropriate levels of protein intake. In the Eastern United States, Weitzel (2019) demonstrated

22 that the overall foraging efficiency of hunted prey gradually declined in the middle Tennessee

23 River; occupants responded by gradually intensifying their resources through dietary 
1 diversification. Finally, in the Mimbres Valley of New Mexico, Cannon (2001) investigated

2 whether people there adopted farming as a form of resource intensification. As in Flannery's

3 BSR, dietary diversification might have played a precursory role in plant domestication in North

4 America. Cannon documented that prey resource depression took place in the period

5 immediately before the appearance of domestication in the region. Based on these results,

6 Cannon argued that cultivation was indeed a form of resource intensification.

7 Recent studies have shown that, even in situations with long-term intensification trends, such

8 tendencies may not be unidirectional or uniform across habitats. Weitzel (2019), for example,

9 pointed out that, although foraging efficiency progressively declined in wetland patches, the

10 same did not occur in terrestrial patches, where there was a general increase in foraging

11 efficiency before initial domestication. Similarly, in a large faunal analysis from the Late

12 Archaic through the Hohokam post-Classic period of the Sonoran desert, Dean and colleagues

13 identified a pattern of intensification via diversification of hunting strategies, which seems to

14 have taken place in the time leading up to the adoption of farming (Beaver and Dean 2019; Dean

15 2007, 2017). However, for the Hohokam groups in this study, the adoption of agriculture created

16 constraints on hunting intensification through gendered labor demands associated with canal

17 irrigation and associated anthropogenic modifications to the landscape.

18 Investment is the last aspect of intensification. Humans and other animals differ in the degree

19 to which they rely on technology to interact with their environment. Humans use a wide array of

20 tools and features as part of their subsistence technology (Oswalt 1976). Hunters use weapons,

21 tools, and structures to help them trap and kill their prey, process their carcasses, store animal

22 products, cook or transform animal products into food and other useful products (e.g., clothes,

23 shelter), and increase resource production when under population pressure (Flannery 1972:417). 
1 As discussed above, there is an assumption that better technology increases the number of

2 resources acquired. However, that technology comes with a cost of time (labor) to acquire the

3 raw material, produce the technology, and maintain or repair that technology (e.g., Bleed 1986;

4 Bright, et al. 2002; Kuhn 1994; Metcalfe and Barlow 1992). As Ugan et al. (2003) note, the costs

5 of technology are just as substantial as the benefits derived from its use. We keep in mind two

6 factors when comparing the time cost of technology. The first is the actual time invested in the

7 creation and use of technology. The second is the time that hunters would otherwise spend

8 foraging if the technology were not involved. As with all technology, its use is not always

9 functional for maximizing returns. Decoration, construction, and use of technology also have

10 symbolic or social values that are not viewed the same as caloric returns.

11 Since Flannery formulated and popularized the idea of the BSR as a type of resource

12 intensification, researchers have focused on discovering other formal intensification mechanisms

13 that have driven many large-scale human economic transitions, often using zooarchaeological

14 data. This study documents the intensification mechanisms employed over time on the Great

15 Plains. In the following section, we provide a brief background on the cultural history and

16 environmental constraints of this region.

\section{GREAT PLAINS CULTURES AND PALEOENVIRONMENT}

18 This study expands on our earlier work examining the processes and resulting patterns of

19 animal use across the Great Plains and adjacent regions during the Paleoindian period in the

20 context of the longer term cultural history of the area. In particular, we assess whether the

21 apparent habitat differences in prey choice observed during the Paleoindian period are present

22 later by tracking changes in the long-term foraging practices of peoples on the Great Plains. The

23 archaeological record of this region covers a 13,500-year period of significant climatic and 
1 environmental changes. We discuss the degree to which shifts in human demography, mobility,

2 and technology affected subsistence practices geared toward the intensification of resource

3 production.

$4 \quad$ Before European settlement, a complex series of grassland plant and animal communities

5 inhabited the North American Great Plains. The story of these biological communities began

6 during the grassland expansion that occurred approximately 5-7 million years ago. Increased

7 climatic aridity catalyzed this shift during the Miocene-Pliocene transition. The resulting decline

8 in woodlands promoted an increased abundance of $\mathrm{C}_{4}$ grasses and facilitated the coevolution of

9 mammals adapted to grazing and open habitats (Anderson 2006; Axelrod 1985; Mack and

10 Thompson 1982). These factors shaped the composition of the Great Plains grasslands' biological

11 communities and their organismal characteristics. Particularly crucial to the evolution of human

12 occupation in this region, the Plains hosted the coevolution of a mutually beneficial relationship

13 between large mammal grazers and primary producers (grasses). At least as far back as the

14 Pleistocene-Holocene transition, the structure of this and other community interactions varied

15 according to the Great Plains' west to east precipitation cline and its north to south temperature

16 gradient (Küchler 1965; Tieszen, et al. 1997).

17 Tallgrass or mixed-grass prairies occurred across most of the eastern Plains. Greater

18 precipitation trends along the eastern borders of the Plains supported tallgrass prairie grasses

19 intermixed with oak, walnut, and hickory woodlands. Mixed-grass prairies and some gallery

20 forest along major riverways covered the central Plains (Iowa, Missouri, Kansas). The western

21 portion of the Plains became true shortgrass prairies, stretching to the front range of the Rocky

22 Mountains (Coupland 1992; Küchler 1965; Tieszen, et al. 1997; Weaver 1968). A high degree of 
1 spatial and temporal variability in climatic conditions over time influenced the distribution of

2 vegetation and fauna, and instigated dramatic shifts in human land use and subsistence activities.

3 The gradients of temperature and precipitation on the Great Plains mean that the

4 northwestern portions are generally cooler and drier. In comparison, the southern and eastern

5 portions are generally warmer and wetter (Tieszen, et al. 1997). This environmental variation

6 underlies a gradient of grass adaptation, most notably reflected in the morphological cline

7 ranging from tall to short grass species. Such evolutionary adaptations shaped an inverse

8 relationship between grass height and the total edible portion of the grass (Frank, et al. 2002;

9 Frank and Mcnaughton 1993; Frank, et al. 1998; McNaughton 1984). As a result, the western

10 short grasses of the High Plains likely supported higher concentrations of large grazers than the

11 mixed-grass or tallgrass prairies (Frank and Mcnaughton 1993; Otárola-Castillo 2016). Except in

12 times of extreme drought, hunters would have likely found the High Plains region to be the most

13 productive big prey hunting area. After horticulture emerged in this region, the wetter and

14 warmer conditions, including the higher levels of nitrogen in the soil, made the tallgrass prairie

15 and eastern mixed-grass settings more attractive for dryland farming (Lauenroth, et al. 1999).

16 Native cultures have existed on the Great Plains since at least 13,300 years ago, although

17 claims that occupations of the Plains and adjacent areas took place as much as 15,000 years ago

18 are currently being debated (Miller 2018; Waters 2019). The first archaeological period

19 (Paleoindian) on the Great Plains dates from approximately 13,300-8000 years ago.

20 Paleoclimatic research of the Great Plains suggests that the Paleoindian period was generally

21 cooler than later in the Holocene, with higher effective moisture and a high frequency of

22 fluctuations in temperature regimes (e.g., Dansgaard, et al. ; Williams, et al.). Following the

23 retreat of the Laurentide glacier in roughly $8000 \mathrm{BP}$, the eastern portion of the northern Plains 
1 saw a gradual transition from largely parkland vegetation to a mixed-grass savanna. Temperate

2 grassland vegetation covered the northwestern Plains, including more scattered forests and

3 parklands (Betancourt, et al. 2001; Dean and Schwalb 2000; Yansa 1998, 2006). In the southern

4 Plains, although some eastern regions have shown evidence of forests (especially before about

$59000 \mathrm{BP}$ ), grasslands or savanna conditions dominated most of the region, except with some

6 scattered trees in well-water valleys (Balinsky 1998; Betancourt, et al. 2001; Bousman 1998;

$7 \quad$ Fredlund, et al. 1998; Holliday 1995; Johnson 1987; Theler 2003).

$8 \quad$ Groups living during this period maintained high degrees of residential mobility, but

9 exhibited significant technological and economic differences from one another compared to in

10 later periods. There is a paucity of direct archaeological evidence for the use of plants or the

11 presence of plant processing equipment (Adair and Drass 2011; Blackmar and Hofman 2006).

12 Some Clovis-age Plains sites have yielded evidence of human artifacts in direct association with

13 remains from extinct species, including mammoth, mastodon, bison, camels, and horses,

14 suggesting that human predation may be one factor contributing to the loss of those animals in

15 North America (Broughton and Weitzel 2018; Meltzer 2015; Surovell and Waguespack 2009;

16 Widga, et al. 2017).

17 A research question that has generated much attention is whether Great Plains Paleoindians

18 specialized in hunting big game. While there is little consensus on this topic, it is empirically

19 challenging to rigidly categorize Paleoindian groups as solely specialized or generalized

20 foragers, as evidence across sites shows substantial use of large, medium, and small prey. It is

21 likely most appropriate to characterize these foragers as having practiced a seasonally and

22 geographically flexible economy (Cannon and Meltzer 2008; DeAngelis and Lyman 2018; Hill

23 2007a, 2008; Kornfeld 2007; Kornfeld and Larson 2008; Surovell and Waguespack 2008). 
1 However, with the extinction of the Pleistocene megafauna, bison became the primary large-

2 body prey, and archaeologists have discovered numerous single- and repeat-event bison kill

3 localities across the Plains (Bozell, et al. 2011). Bison hunting was a year-round activity, with

4 most kills being relatively small and probably organized and executed by a single extended

5 family (Hill 2013). Nonetheless, some Paleoindian groups, like the Cody complex, were skilled

6 at conducting enormous, likely communal bison kills (>100 animals), at least on occasion

7 (Bamforth 2011; Hill 2013; c.f. Hofman 1994).

8 The early to middle Holocene drying appears to have been a significant climatic event. The

9 warmer, drier conditions led to the increasing dominance of drought-tolerant grasslands covering

10 much of the Plains. Primarily during severe drought, bare areas may have formed on the upland

11 surface vegetation. Especially in central and southern regions of the Great Plains, the loss of

12 surface vegetation resulted in massive eolian sedimentation and alluvial downcutting during this

13 period (Bettis III and Mandel 2002; Forman, et al. 2001; Halfen and Johnson 2013) Drought

14 conditions also resulted in significant declines in the availability of surface water. In the

15 Northeast, this often resulted in the appearance of more brackish wetlands, while in the south and

16 far west, many springs and streams disappeared (Holliday 1995; Johnson 1987).

17 Starting around 6000 BP (and established by about 4000 BP), conditions across the Great

18 Plains became cooler and wetter - conditions that have continued to modern times (Barnosky

19 1989; Clark, et al. 2002). The expression and timing of this climatic amelioration varied across

20 the region. In the dry western Plains, increased precipitation reactivated spring-fed streams and

21 marshes around 4500 BP. In the northern Plains, increased precipitation meant that short-grass

22 prairie vegetation cover was sufficient to cease or at least dramatically slow soil erosion during

23 the late Holocene. Despite the cooler and wetter conditions of this period, the late Holocene 
1 exhibited cyclical wet-dry periods. Some of the drought periods were quite severe and

2 multidecadal, even lasting a century (Clark, et al. 2002; Halfen and Johnson 2013; Shuman and

3 Marsicek 2016). These extended drought periods were so intense that they reactivated dune

4 fields and increased eolian activity. In the warmer and drier central and southern plains, these

5 droughts contributed to severe erosion in the small alluvial valleys, which would then aggregate

6 in the more extensive alluvial valleys (Bettis III and Mandel 2002; Robertson 2011)

$7 \quad$ Researchers have argued that generalized hunting-gathering economies characterized the

8 Archaic period (8000-2000 BP), with increasing regional differences in terms of technology,

9 subsistence, and mobility. In many parts of the Great Plains, the Archaic economies and lifeways

10 differed greatly from those of Paleoindian groups (Blackmar and Hofman 2006; Frison 1998a,

11 1998b). Unlike in the Paleoindian period, however, periodic droughts during the Archaic may

12 have resulted in the depleted use or even abandonment of the driest portions of the plains

13 (Meltzer 1999). Bison procurement of mostly cow-calf herds continued throughout this period

14 across much of the plains (Frison 1998a, 2001; Johnson 1987; Widga 2004, 2006). Mass

15 communal kills were often conducted with the addition of jumps, arroyo traps, or surrounds,

16 mostly in the northwest and southern Plains (Byerly, et al. 2005; Frison 1970, 1998a, 2001;

17 Lobdell 1973; Mulloy 1954). At least 5000 years ago, these large-game hunters began to extract

18 bone grease from carcasses (Walker 1992). Bison were, of course, not the only prey used by

19 Archaic groups; evidence has indicated the importance of deer, pronghorn, elk, fish, rabbits,

20 rodents, reptiles, and mussels in the diet, although these might have functioned as secondary

21 resources (Ahler and Toom 1995; Dyck and Morlan 2001; Haury 2005; Schmits 1978; Widga

22 2004). 
1 On the eastern portions of the Plains, Archaic groups demonstrated a higher degree of

2 sedentism and more complex and diversified adaptions than other Plains Archaic groups (Adair

3 and Drass 2011:309; Kay 1998). Archaic groups introduced new technologies to the Great

4 Plains, including bone and clay beads (Schmits 1978; Thies 1990) clay effigies (Witty and

5 Reynolds 1982), fiber-tempered ceramics (Reid 1983), chipped stone harvesting tools (Witty and

6 Reynolds 1982), grinding stones, and earth ovens. Evidence for the use of plants became

7 increasingly more common than in earlier periods, especially in the eastern Plains during the

8 Archaic (Adair 2006; Adair and Drass 2011; Kay 1998).

9 The Woodland period (2500-1000 BP) was a time of major regional social and economic

10 innovation. Indigenous people across much of the Plains began to make and use ceramic vessels

11 regularly, enabling improved efficiency in cooking and grease extraction. Other economic shifts

12 occurred as people gradually switched from the atlatl to the bow-and-arrow and added the

13 cultivation of domesticated plants to their repertoire of wild plant foods (Adair and Drass 2011;

14 Johnson and Johnson 1998). Population size and residential sedentism significantly increased

15 during the Woodland, especially in the eastern Plains. People became more socially integrated

16 during this period. This greater group cohesion is indicated by the communal use of burial

17 mounds and extensive sharing of technologies, symbols, and rituals (Adair 2012; Adair and

18 Drass 2011).

19 In the drier western and the northern Plains, some groups remained aceramic societies that

20 continued to extensively use bison and pronghorn (Bozell, et al. 2011; Frison 1998a, 2001;

21 Johnson 1987; Kehoe 1973). In the far northwest, several Woodland sites, such as Head-

22 Smashed-In, Gull Lake, and Wardell, reflect intensive and repeat mass harvesting of bison. At

23 sites like these, very large, stratified bison bonebeds have been found at the base of cliff faces or 
1 associated with corral structures (Frison 2004; Kehoe 1973; Kornfeld, et al. 2010). In the east,

2 groups adopted a horticultural economy, became less mobile, and hunted fewer bison. However,

3 they consumed a substantially broader diet of medium- and small-bodied animals. In these areas,

$4 \quad$ Woodland people consistently exploited a wide range of taxa in their diets, including low-ranked

5 fish, birds, turtles, and various small mammals, alongside larger prey such as deer and bison

6 (Wismer 2018). Common elements at many Woodland sites were stone-filled pits and hearths

7 associated with roasting and cooking meat and grease extraction.

8 In the last 1000 years of prehistory, a diverse array of Late Prehistoric groups appeared

9 across the Plains, characterized by considerably larger population sizes. Late Prehistoric people

10 were more dependent on agriculture than their earlier Woodland counterparts. However, they

11 used similar native seed crops and introduced new cultigens (maize, bean, squash). Late

12 Prehistoric sites reflect a high level of sedentism, usually marked by the construction of large

13 houses used year-round and a greater intensity of farming. Initially, farming communities were

14 small, ranging from individual farmsteads to hamlets. Later, many people organized into large

15 permanent villages. Ceramic technology became prominent, serving multiple functions (e.g.,

16 cooking, storage) and beginning to reflect regionally distinct technological traditions. These

17 societies were largely economically self-sufficient, but often participated in extensive exchange

18 networks involving groups within and outside the Plains.

19 Despite the importance of agriculture, with few exceptions, hunting was still an essential

20 part of Late Prehistoric economies. Massive bison kills took place, especially in the northwestern

21 Plains. Although communal hunts were probably not utilized everywhere, nonetheless, bison

22 continued to be a central part of the subsistence across most of the Plains (Bozell, et al. 2011).

23 Later groups developed a dual economic system composed of hunting and farming, organizing 
1 logistical parties for the long-distance hunting of bison scheduled around the planting and

2 harvesting seasons. However, most hunting probably focused on more locally available

3 resources, including deer and elk, combined with the use of a diversity of smaller prey, including

4 rabbits, turtles, dogs, furbearers, rodents, and a variety of fish. In this context, the central Plains

5 tradition in Kansas and Nebraska seems unique, as these groups relied on a generalized broad-

6 spectrum economy; there is minimal evidence for the use of bison, except at localities in the

7 High Plains.

8 In the next section, we introduce our framework for characterizing Great Plains’ peoples

9 dietary strategies. We use this framework to develop predictions on the level of specialization

10 and diversification expected across habitats (alluvial valleys, plains and rolling hills, and

11 foothills and mountains) and time periods (Paleoindian, Archaic, Woodland, and Late

12 Prehistoric).

In general, behavioral signatures of diversification and specialization indicate a variable

15 investment in "hardware” and "software.” Hardware may consist of novel food procurement

16 technologies, for example, storage or prey capture facilities, development and use of nets, or new

17 hunting equipment. Software refers to culturally normalized strategies for increasing food

18 production, such as prey mass capture events, increased labor inputs, divisions of labor by age

19 and sex, degree of carcass processing, resource-life extension through storage, and the logistical

20 organization of labor to resolve scheduling conflicts (Reitz and Wing 1999).

21 Dietary diversification and specialization strategies are likely the result of a continuum of

22 subsistence behaviors. We assume that if small-scale societies practice such strategies, their

23 archaeological record will reflect secular trends in their subsistence behaviors. Researchers have 
1 characterized these trends using sophisticated methods to account for the number of species

2 (species richness) and the abundance of each species included in the diet (species evenness). For

3 example, Figure 1 illustrates a simple one-dimensional gradient of low to high species richness.

4 This figure visualizes the trend of an idealized forager diet focused on large-animal

5 specialization (low diversity) versus one in which there is an increase in dietary diversification

6 (high diversity). However, by not accounting for evenness, Figure 1 might mask a pattern of

7 specialization and characterize it as diversification. In Figure 2, the specialization-diversification

8 continuum remains, but we add each species' abundance, characterized by evenness, as an

9 additional axis to this space, creating four possible dietary configurations.

10 Specialization. Here, we call specialization an assemblage exhibiting a pattern of high

11 richness and low evenness. Although hunters target several species, there is a clear

12 predominance of a single species or size-class.

13 Hyper-Specialization. We refer to hyper-specialization as the pattern characterized by low

14 richness and low evenness. In this case, the low species representation is not only dominated by a

15 single species but can also be a single species.

16 Diversification. We define diversification here to be assemblages that exhibit high evenness

17 but low species richness. Evenness values show greater uniformity of hunting effort. This pattern

18 no longer shows dominance by a single species or taxon, and even in low species representation,

19 there is a tendency for equal species abundance.

20 Hyper-Diversification refers to a pattern of high evenness and high richness. This pattern of

21 "jack of all trades, master of all" shows no apparent preference for any single species or taxon.

22 High evenness values signify an equal abundance of all species represented, perhaps signifying

23 hunting mastery of all species in the diet. 


\section{RICHNESS}

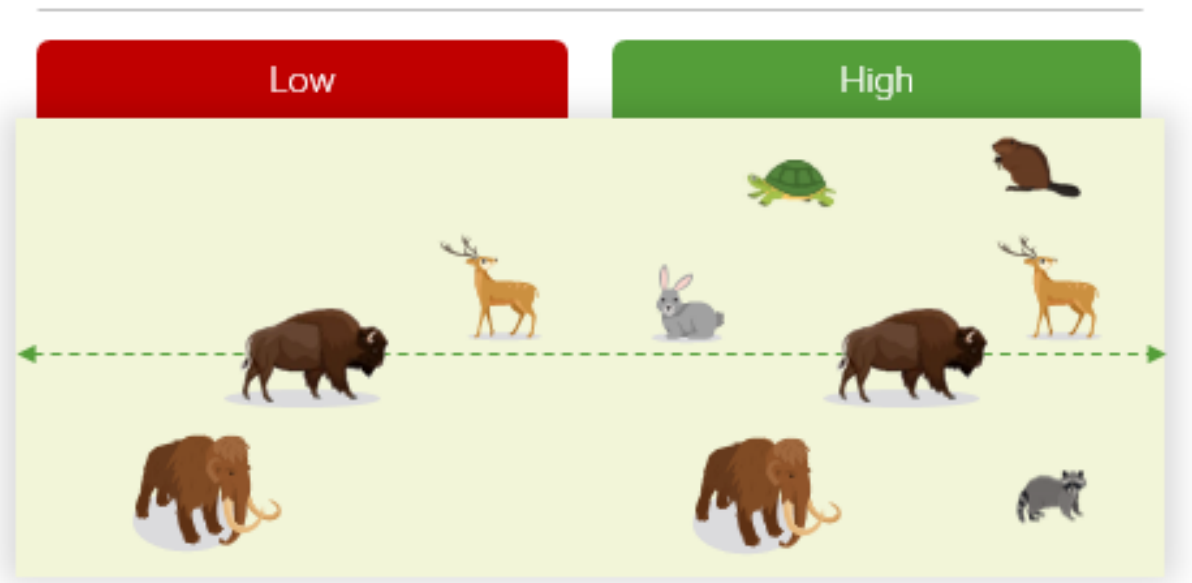

Specialization

Diversification

Not many species represented Many species represented

Figure 1. Graphic depiction of variation in prey richness in an idealized forager's diet on a one-dimensional gradient from a specialized diet focused on large game to one with high prey diversification 
Low species representation, similar abundance of each species
Many species represented, similar abundance of each species

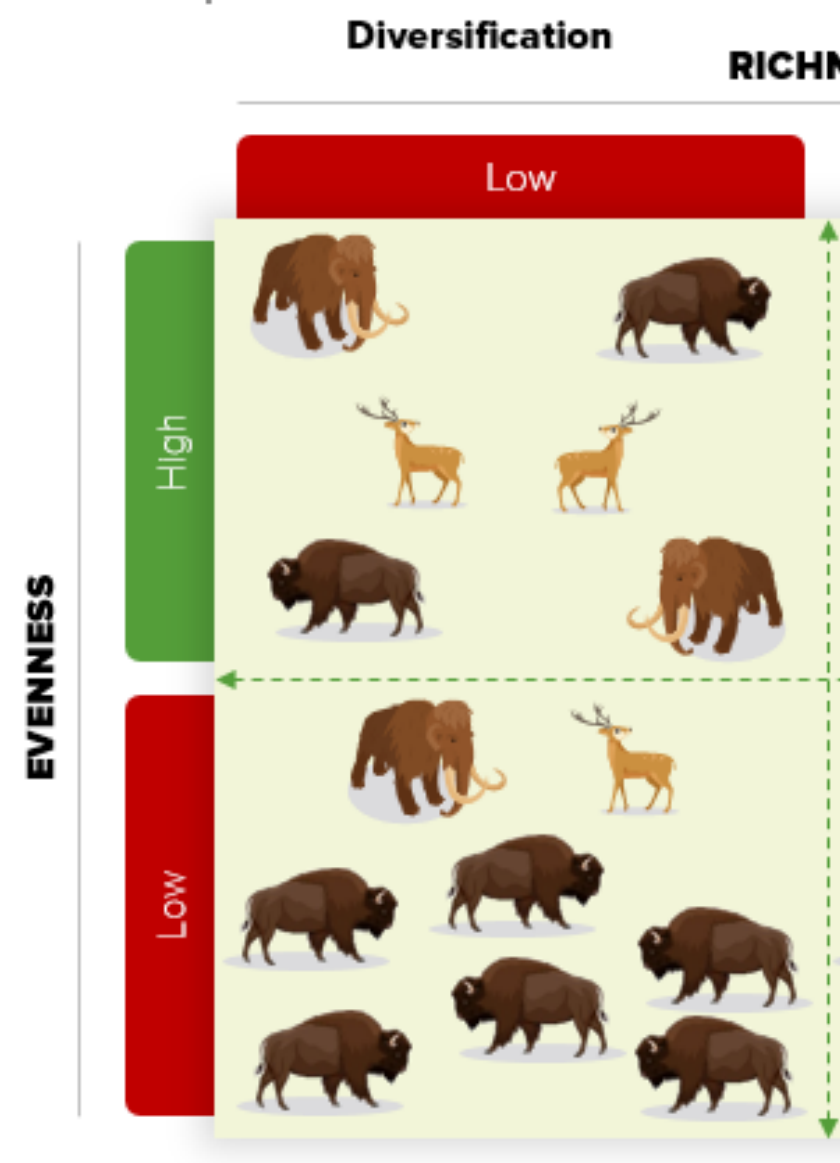

Hyper-Specialization

Low species representation, assemblage dominated by a common species
Hyper-Diversification

Figure 2. Graphic depiction of variation in prey richness and evenness. This "diversification space" illustrates the in an idealized forager's diet on a two-dimensional gradient from a hyper-specialized diet composed of low species representation and dominated by the large game, to a diet that is hyperdiversified representing many species at a similar abundance.

The literature shows that there has been limited systematic and quantitative work on changes in long-term animal use across the Great Plains (e.g., Bozell, et al. 2011; Johnson 1986,

8 1987; Semken Jr and Falk 1987). Despite this limitation, we expect there to be a trend of

9 increasing dietary diversity among Great Plains hunters, as outlined above. The prehistoric

10 people who lived on the North American Great Plains experienced a remarkable range of 
1 climatic, environmental, and cultural variability over the last 13,000 years. There is good reason

2 to expect that their archaeological remains can track fundamental changes in human-animal

3 interactions through time. We anticipate that Paleoindian and Archaic foragers had more

4 specialized economies. The traditional perspective is that Paleoindians made extensive use of

5 mammoth and bison. However, they also included a wide variety of lower ranked resources in

6 their diet, depending on the season and habitat.

$7 \quad$ The increasing temperatures and drought conditions during the Holocene Climatic

8 Optimum likely negatively affected the natural abundance of large ungulates such as bison. We

9 expect that this significant climatic change would have made it difficult to sustain heavy

10 predation on bison across the region. In places where bison or other large game were less

11 affected, Archaic groups likely maintained a fairly specialized diet; however, in places most

12 affected by drought, we anticipate that hunters would have either abandoned these regions and/or

13 increased their dietary diversification by increasingly procuring more readily available small

14 animals.

15 The last few millennia likely witnessed a rebound of bison populations as more mesic

16 conditions became established across the region. This recovery potentially caused a resurgence

17 of bison hunting during the Woodland and Late Prehistoric periods. However, the economies of

18 Woodland groups would have had to respond to increased population pressure and sedentism far

19 beyond anything prior groups had experienced. This demographic packing probably amplified

20 predation pressure on crucial prey. Hunters likely responded by further increasing the diversity

21 of species in their diets and more evenly hunting all prey available. We therefore expect that the

22 Woodland economies were the most diverse compared to the other periods, with small mammals,

23 birds, and aquatic resources becoming more common in people's diets. However, the expected 
1 increase in bison on the landscape would have still made it quite attractive to hunt large prey, if

2 small family groups could find ways to manage the competing labor demands of gathering wild

3 plants, managing their horticultural pursuits, and making hunting forays increasingly farther

4 away from human settlements.

5 The Late Prehistoric period witnessed a further increase in population sizes and the formation

6 of aggregated settlements. In places across the Great Plains, Late Prehistoric groups were likely

7 intensive agriculturists living in large, permanent villages. Under these demographic and land

8 use conditions, we anticipate that hunting took on a dual nature, as hunters specialized in large

9 and small prey alike. Large-prey hunting likely became more critical, especially seasonally;

10 however, due to technological developments (e.g., bow and arrow) and social reorganization

11 (e.g., a division of labor by age and sex), these groups likely also relied heavily on a broad

12 spectrum of lower ranked resources. Simultaneously, as settlements became more tethered to

13 particular plots of land where farming was possible, the emphasis would have been on local

14 resources. At the same time, it is also possible that the increasing social complexity and

15 intergroup cooperation and competition among Late Prehistoric populations may have prompted

16 some society members to undertake the increasingly inefficient and risky task of acquiring bison,

17 despite the high risk of mortality and failure, and low caloric returns involved in such strategies

18 (Smith 2004; Wiessner 2002).

MATERIALS AND METHODS

20 The current study examines faunal use at one of the largest geographic and spatial scales

21 possible: trends across generations of multiple local groups. As noted previously (Cannon and

22 Meltzer 2008; Moss 2012), the best approach to studying subsistence change is by determining

23 how contemporary sites within a settlement function with resource variability. We accept that 
1 this large scale limits our ability to consider the effects of localized or, in some cases, even

2 regional climatic and environmental changes on subsistence practices. We do not question the

3 value of studies focusing on resource use within locally specific ecological, social, and historical

4 frameworks; however, our study tries to consider large-scale trends in order to understand the

5 full range of subsistence strategies. Organizing our analysis of faunal use around habitat setting

6 differences is an attempt to factor in the natural effect that variation in resource availability

7 might have had on the prey choice decisions of contemporary foragers.

8 Our project collected data on taxa abundance from 204 archaeological components from 116

9 archaeological sites across the Great Plains and the adjacent Rocky Mountains. Sites used in this

10 study range in age from approximately 13,477 to $300 \mathrm{cal}$. BP, with geographic distribution

11 across all the major zones of the Great Plains and adjacent Rocky Mountains and its foothills

12 (Figure 3). These data were derived primarily from published reports (see discussion of methods

13 in Hill 2007b; Hill 2008; Otárola-Castillo 2016). We used only assemblages from residential

14 camp localities because assemblages from special-use kill localities would likely have biased the

15 sample toward a focus on large fauna. We expect kills to lack the dietary variation anticipated at

16 residential camps. We followed the site function definitions established by Sellet (1999) and

17 Wheat (1978), and followed Hill's (2008) criteria system for assigning sites to different habitats

18 (alluvial valleys, plains and rolling hills, and foothills and mountains). We determined temporal

19 associations (Paleoindian, Archaic, Woodland, and Late Prehistoric) for each assemblage using

20 available dates and the presence of diagnostic artifacts. We chose habitat designations to reflect 


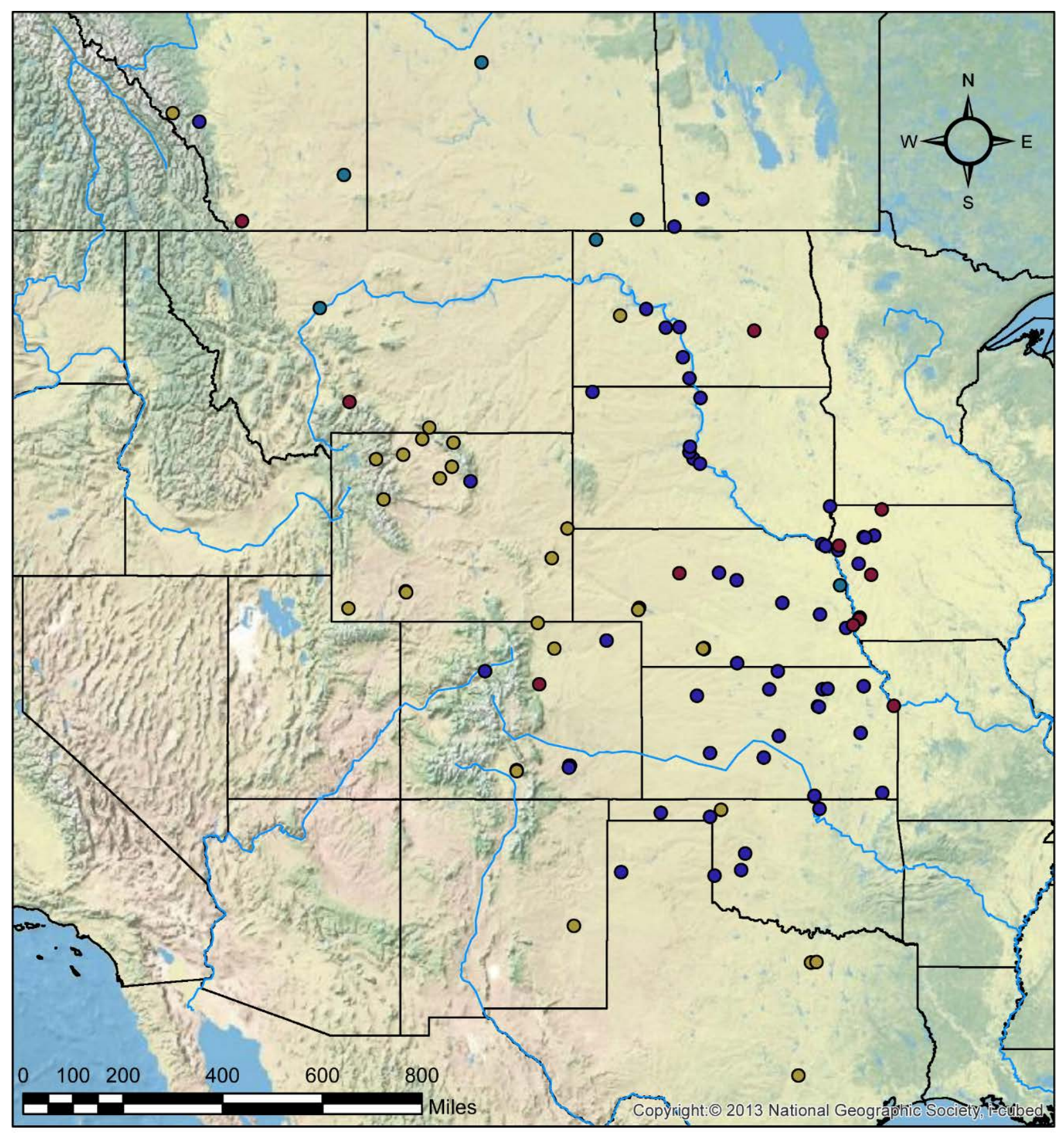

\section{○ Paleoindian ○ Archaic ๑ Woodland ๑ Late Prehistoric}

Figure 3. Map of the Great Plains and adjacent Rocky Mountains, including site locations for the archaeological components used in this study

1 the key environmental zones exploited by past foragers and farmers, which differ in terms of

2 resource productivity (e.g., patch caloric returns) and predictability (Knell 2007; Kornfeld 1997).

3 As discussed previously (Hill and Knell 2013; Knell and Hill 2012), foragers and farmers would 
1 have found habitats to be quite different in terms of resource availability, abundance, and

2 seasonal and spatial predictability. Mountains and foothills and alluvial valleys were likely

3 calorie-rich areas with highly predictable and abundant biotic resources, and good sources of

4 valuable abiotic resources (i.e., water, wood, and tool stone). By contrast, plains and rolling hills

5 would have had a low abundance of biotic resources that were temporally and spatially

6 unpredictable and critical abiotic resources that were spaced far apart.

7 In total, the sites used in this study contained 459,122 faunal specimens, including

8 unidentified fragments. For our study, this dataset contained 332,099 specimens that could be

9 quantified as Number of Identified Specimens (NISP), of which more than 176,364 (53\%) were

10 identified to genus or finer taxonomic distinction. Following the general criteria outlined by

11 Grayson and Meltzer (2002) and Cannon and Meltzer (2004:1959-1960), we included only

12 faunal remains that showed unequivocal evidence of human butchery and consumption or were

13 reported to be associated with cultural features or deposits.

14 We utilized three diversity measures to investigate multiple aspects of diet breadth in this

15 study. The Margalef Diversity Index ( $\mathrm{D}_{\mathrm{Mg}}$ ) (Clifford, et al. 1975) is a simple richness measure

16 that attempts to compensate for sample size differences by dividing the number of species

17 present $(S)$ by the total NISP in the assemblage $(N)$, using the following equation (Magurran

18 2004: 77):

19

(1) $D_{m g}=\frac{S-1}{\ln (N)}$

20 An increase in $\mathrm{D}_{\mathrm{mg}}$ indicates that a greater number of species are being consumed, which

21 indicates a lack of specialization in the diet. 
1 To explore the degree of hunting focus on any single species or group of species, we used the

2 Simpson's Index $\left(\mathrm{D}^{\prime}\right)$ (Levins 1968; Simpson 1949). This index is calculated using the formula:

$3 \quad$ (2) $D^{\prime}=\sum\left(\frac{n i(n i-1)}{N(N-1)}\right)$

4 where $n_{i}$ is the abundance of taxon $i$, and $\mathrm{N}$ is the total number of individuals (specimens) in the

5 assemblage (Magurran 2004:115). Because $\mathrm{D}^{\prime}$ decreases as evenness increases, we express the

6 Simpson's Index as:

$7 \quad$ (3) $1-D^{\prime}$

8 (Faith and Du 2018:1428) note that, of various evenness measures used by zooarchaeologists, the

9 Simpson's Index (1- $\left.\mathrm{D}^{\prime}\right)$ is superior because it is relatively insensitive to changes in richness and

10 it has greater power to detect minor changes in evenness.

11 The final measure used was the Abundance Index (A.I.) (e.g., Bayham 1979; Broughton

12 1994a; Szuter and Bayham 1989). The A.I. value is calculated by combining NISP counts for all

13 taxa within established body size classes (i.e., Brain 1981; Klein 1976) - size class 1 (live body

14 mass $<22 \mathrm{~kg}$ ), size class $2(22-113 \mathrm{~kg})$, size class $3(113-340 \mathrm{~kg})$, and size class 4 ( $>340 \mathrm{~kg})-$ to

15 determine the contribution of a specific body size class to the entire faunal assemblage. In this

16 case, we used the following equation for large fauna:

17

(4) $A I_{l g}=\frac{\sum \text { Size Class } 4 \text { NISP }}{\sum_{i=1}^{k} \text { Size Class } k_{i} \text { NISP }}$

18 where, $k_{i}$ is the $\mathrm{k}^{\text {th }}$ established body size class (1-4). The resulting index generates an $A I_{l g}$ value

19 ranging between 0 and 1 . High values indicate greater representation of large-bodied fauna in the

20 assemblage. For this study, large-bodied animals generally represented specimens identified as

21 mammoth or bison, or indeterminate specimens that were the size of these animals. 
1 The results from these three diversity measures can provide a perspective on where the

2 foragers and farmers of the Great Plains and the Rocky Mountains fall along the diversification-

3 specialization continuum of faunal use, as elaborated in Figure 2. The possible end values for the

4 species richness and evenness of each assemblage, in this case, were measured by the Margalef

5 Diversity Index and Simpson's Index, respectively.

6 We used the A.I. values to interpret the results further. For example, high values of $A I_{l g}$ in an 7 assemblage with low evenness would indicate that bison or a comparable large-bodied species

8 was the dominant prey species, whereas low $A I_{l g}$ in situations with low evenness would indicate 9 that non-bison species were the dominant prey.

10 The data used in this study could not satisfy key assumptions. For example, sample values of

$11 \mathrm{D}_{\mathrm{Mg}}, 1-\mathrm{D}^{\prime}$ and $A I_{l g}$ were not distributed and thus exhibited Gaussian ("normal") errors. To

12 account for this problem, we conducted statistical comparisons using generalized linear(GLM) in

13 the R computing environment (R Core Team 2020). GLM allows users to apply a more

14 appropriate distribution to model the sample's distribution error within a familiar ANOVA-like

15 environment. Values of $\mathrm{D}_{\mathrm{Mg}}$ were truncated at 0 and theoretically continued to infinity. The

16 Gamma function is a distribution that models such an outcome and so was used to model this

17 variable using the glm() function in R's base stats package. The $A I_{l g}$ and 1 - $\mathrm{D}^{\prime}$ values are

18 essentially proportions, distributed in a bimodal fashion with large proportions of 0 s and $1 \mathrm{~s}$. As

19 such, we analyzed these data using beta regression, using the R package betareg (Cribari-Neto

20 and Zeileis 2010).

21 After modeling was complete, we estimated the means and standard errors in order to make

22 comparisons within and between habitat and time group factors using the marginal means (least-

23 squares-means). Marginal means are recommended for ANOVA-like comparisons because they 
1 are more robust to sample size differences. We computed the marginal means using the emmeans

2 package (Lenth 2020).

3

4

5 dataset, and not all groups are equally represented $\left(\chi^{2}=42.09, \mathrm{df}=6, \mathrm{p}<.00001\right.$, Cramer $\left.\mathrm{V}=.321\right)$

6 (Table 1; Appendix 1). Based on standardized residuals from the $\chi^{2}$ analysis, alluvial valley

7 settings are underrepresented and foothill and mountain localities overrepresented in the

8 Paleoindian period, whereas, in the Archaic period, there is a slight underrepresentation of

9 plains/grassland localities. Both the Woodland and Late Prehistoric periods show an

10 overrepresentation of alluvial valley sites and an underrepresentation of foothills/mountains and

11 plains and rolling hills habitats. The Late Prehistoric period also has an overrepresentation of

12 sites in the plains and rolling hills. Given that this study explicitly considers the interaction

13 between period and habitat, minor differences in habitat frequency over time should not

14 significantly bias our results, especially since the sample size is adequate, at least for the

15 Paleoindian, Archaic, and Late Prehistoric periods. At the same time, the very small size of the

16 Woodland sample is problematic. Although the marginal means technique we outlined in the

17 methods section can help with the sample size problem somewhat, we limited ourselves to

18 making inferences about relatively larger samples (>10). Because of these sampling issues, we

19 omit the standard error bars from some plots to show that the results come from small samples.

20 Our Margalef and Simpson's Index values are negatively related, with a statistically

21 significant correlation of -.76. While the relationship is not linear, it is visually evident that if it

22 were linearized, the correlation would be more substantial. 


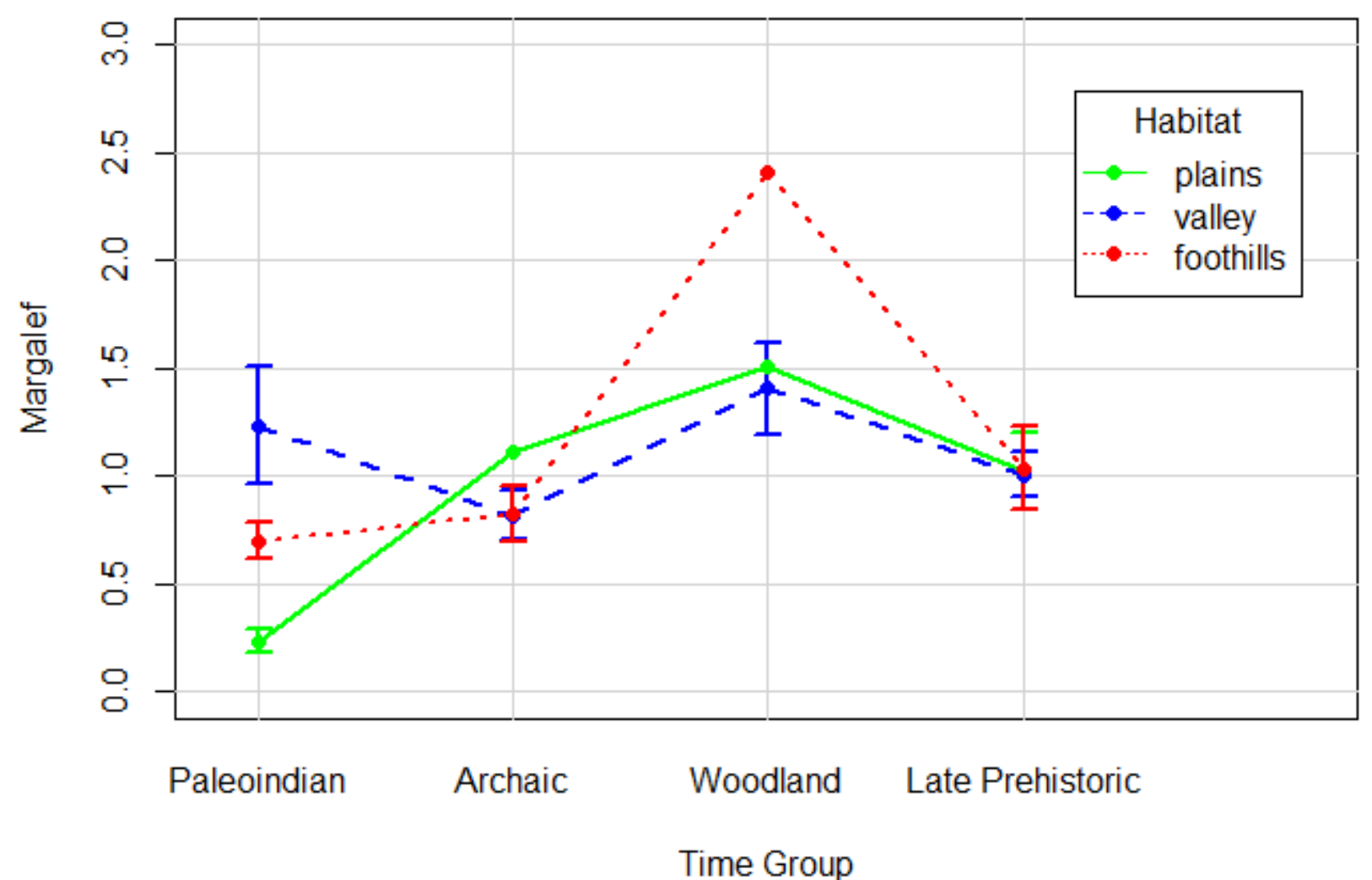

Figure 4. Estimates of mean Diversity Index (Dмg) values of species (with 95\% Confidence Intervals). This plot illustrates estimates across habitats (alluvial valleys, plains and rolling hills, and foothills and mountains) for the Paleoindian, Archaic, Woodland and Late Prehistoric periods. Means and confidence intervals were calculated using a Generalized Linear Model (GLM) and a gamma distribution. Estimates without Cls had small sample size (see text).

1 Margalef Diversity Index

2

The plains and rolling hills habitat during the Paleoindian period has the lowest Margalef

4 Diversity Index value $\left(D_{\mathrm{Mg}_{\mathrm{g}}}=0.237 \pm 0.056\right)$ observed for any time or habitat (Figure 4; Table 2).

5 Margalef values for Paleoindian sites in alluvial valleys $\left(D_{м \mathrm{~g}}=1.237 \pm 0.276\right)$ and foothills and

6 mountains $\left(\mathrm{D}_{\mathrm{Mg}}=0.700 \pm 0.081\right)$ are significantly higher than for the plains and rolling hills $(\mathrm{p}=$

$7 \quad 0.0004$ and $\mathrm{p}<0.0001$, respectively), but do not differ from each other.

8

9 During the Archaic period, Margalef values for plains and rolling hills $\left(\mathrm{D}_{\mathrm{мg}}=1.112 \pm\right.$

10 0.556) more than quadruple during the Archaic period compared to the Paleoindian values.

11 However, it must be noted that there are only two Archaic plains sites, so these results could be a 
1 function of the small sample size. There are slight declines in the Margalef values for alluvial

2 valleys $\left(D_{\mathrm{Mg}}=0.821 \pm 0.116\right)$ and a slight increase for foothills and mountains $\left(\mathrm{D}_{\mathrm{Mg}_{\mathrm{g}}}=0.826 \pm\right.$

3 0.130). These values do not indicate a significant change in species richness from the

4 Paleoindian period or significant differences between habitats.

5 In the Woodland period, species richness values rise to their highest levels in plains and

6 rolling hills $\left(D_{\mathrm{Mg}_{8}}=1.510 \pm 0.534\right)$, alluvial valleys $\left(\mathrm{D}_{\mathrm{Mg}_{\mathrm{g}}}=1.406 \pm 0.212\right)$, and foothills and

7 mountains $\left(\mathrm{D}_{\mathrm{Mg}}=2.406 \pm 1.202\right)$. However, this change represents a significant increase from the

8 Archaic period only in alluvial valley settings. None of the differences between Woodland

9 habitats are statistically significant, likely due to the very small sample sizes for the

10 foothills/mountains and plains/rolling hills settings.

11 During the Late Prehistoric period, Margalef values decline from Woodland levels across

12 habitats. One notable aspect of the Margalef values for the Late Prehistoric period is that there is

13 no appreciable difference in species richness among habitats. The values for alluvial valley sites

$14 \quad\left(D_{\mathrm{Mg}_{\mathrm{g}}}=1.009 \pm 0.102\right)$, foothills and mountains $\left(\mathrm{D}_{\mathrm{Mg}}=1.037 \pm 0.196\right)$, and plains and rolling hills

$15\left(\mathrm{D}_{\mathrm{Mg}}=1.021 \pm 0.1804\right)$ overlap extensively. In all regions, the values are uniformly low,

16 suggesting that the diets of the Great Plains people at this time were focused on only a few 17 species.

\section{Simpson's Index $\left(1-D^{\prime}\right)$}

The foothills and mountains $\left(1-\mathrm{D}^{\prime}=0.243 \pm 0.037\right)$ and plains and rolling hills $\left(1-\mathrm{D}^{\prime}=\right.$

$210.107 \pm 0.034)$ settings during the Paleoindian period have the lowest Simpson's Index values for

22 any period or habitat (Figure 5; Table 3). Simpson's Index values for alluvial valleys (1- $\mathrm{D}^{\prime}=$

$230.580 \pm 0.080$ ) are significantly higher than for plains and rolling hills and for foothills and 
1 mountains ( $\mathrm{p}=0.0001$ and $\mathrm{p}<0.0001$, respectively, which differ significantly from each other $2 \mathrm{p}=0.006)$.

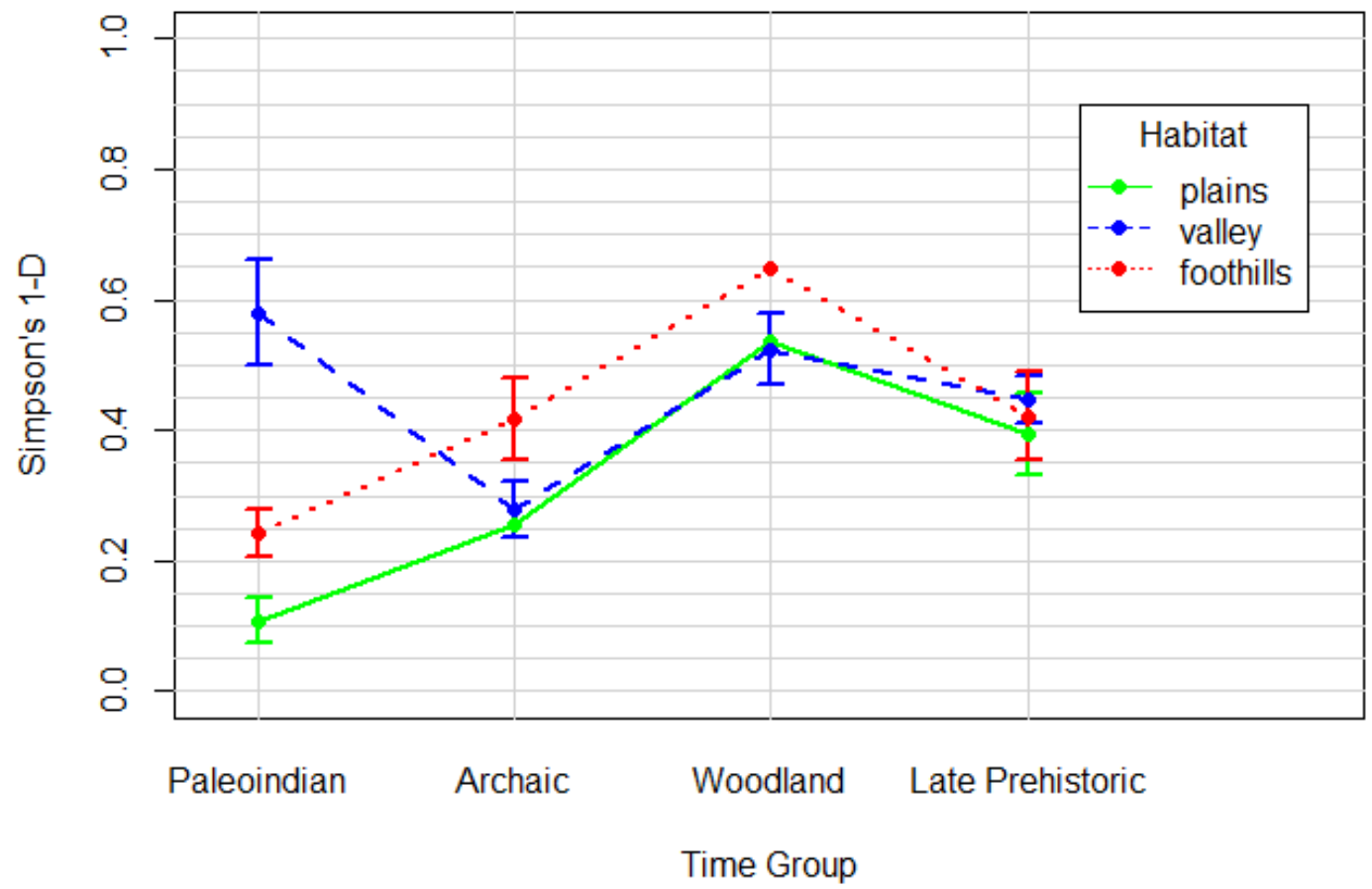

4 Figure 5. Estimates of mean Simpson Index (1-D') values with 95\% Confidence Intervals. This plot 5 illustrates estimates across time and habitats (alluvial valleys, plains and rolling hills, and foothills 6 and mountains) for the Paleoindian, Archaic, Woodland and Late Prehistoric periods. Means and 7 confidence intervals were calculated using a Generalized Linear Model (GLM) using a beta 8 distribution. Estimates without Cls had small sample size (see text). Evenness values rise in both plains and rolling hills $\left(1-\mathrm{D}^{\prime}=0.255 \pm 0.141\right)$ and foothills

11 and mountains ( 1 - $\left.\mathrm{D}^{\prime}=0.416 \pm 0.063\right)$ settings during the Archaic period, but drop in alluvial

12 valley settings $\left(1-\mathrm{D}^{\prime}=0.279 \pm 0.043\right)$. The changes from Paleoindian values are significant for

13 both alluvial valleys ( $\mathrm{p}=.0009)$ and foothills and mountains $(\mathrm{p}=.017)$; however, these two do not

14 differ significantly from each other during this period. If we ignore the plains estimate because of 
1 sample size problems, evenness does statistically change between the Paleoindian and Archaic

2 periods across all habitats.

During the Woodland period, the Simpson's Index values rise across all habitats. The

4 value for foothill and mountain sites $\left(1-\mathrm{D}^{\prime}=0.648 \pm 0.168\right)$ reaches the highest value for any

5 period or habitat, although this increase is reflective of just two sites. The values for the plains

6 and rolling hills $\left(1-\mathrm{D}^{\prime}=0.537 \pm 0.128\right)$ and alluvial valleys $\left(1-\mathrm{D}^{\prime}=0.524 \pm 0.055\right)$ are almost the

7 same, even though their sample sizes are quite different (4 vs. 22 sites, respectively). Only the

8 increase in the value for alluvial valleys is significant compared to Archaic levels ( $p=.0009$ ).

9 There is no statistically significant difference across habitats at the 0.05 level, suggesting a

10 similar, moderate representation of various taxa in the diets. However, we should emphasize that

11 there is a notable increasing trend of species evenness during the Woodland period.

12 During the Late Prehistoric, Simpson's Index values for all habitats decrease from

13 Woodland levels. As observed with the Margalef values, Simpson's Index values for alluvial

14 valley sites $\left(1-\mathrm{D}^{\prime}=0.446 \pm 0.037\right)$, foothills and mountains $\left(1-\mathrm{D}^{\prime}=0.422 \pm 0.067\right)$, and plains

15 and rolling hills $\left(1-\mathrm{D}^{\prime}=0.395 \pm 0.062\right)$ overlap extensively and are not significantly different.

16 Large mammal Abundance Index $\left(A I_{l g}\right)$

17 During the Paleoindian period, $A I_{l g}$ values are uniformly and moderately low $\left(A I_{l g}<.4\right)$

18 across all habitats, suggesting no significant differences in the use of large prey during this

19 period (Figure 6). During the Archaic period, however, $A I_{l g}$ values fall for plains and rolling hill

20 sites compared to Paleoindian levels, whereas values rise in both the foothills and mountains and

21 alluvial valleys. However, only the increase in $A I_{l g}$ value $\left(A I_{l g}=0.625 \pm 0.059\right)$ for alluvial

22 valleys (which reaches its highest level of any period) differs significantly from the Paleoindian

23 period $(\mathrm{p}=.004)$, and from the Archaic values for foothills and mountains ( $\mathrm{p}=0.004)$ and plains 
1 and rolling hills ( $\mathrm{p}=0.003$ ). During the Woodland period, $A I_{l g}$ values drop significantly in

2 alluvial valleys compared to the Archaic period ( $\mathrm{p}=0.0006$ ), but across habitats, there are no

3 significant differences in $A I_{l g}$ values.

As observed with the other analyses, during the Late Prehistoric period, $A I_{l g}$ values are

5 nearly identical across all habitats and at a generally higher level than in previous periods. Large

6 prey seem to compose nearly $50 \%$ of the diets represented by faunal assemblages. This trend

7 suggests that large-bodied fauna represented a large proportion of the animals hunted. These

8 values reflect an increasing reliance on large prey compared to the Woodland period, although

9 this increase is not significant.

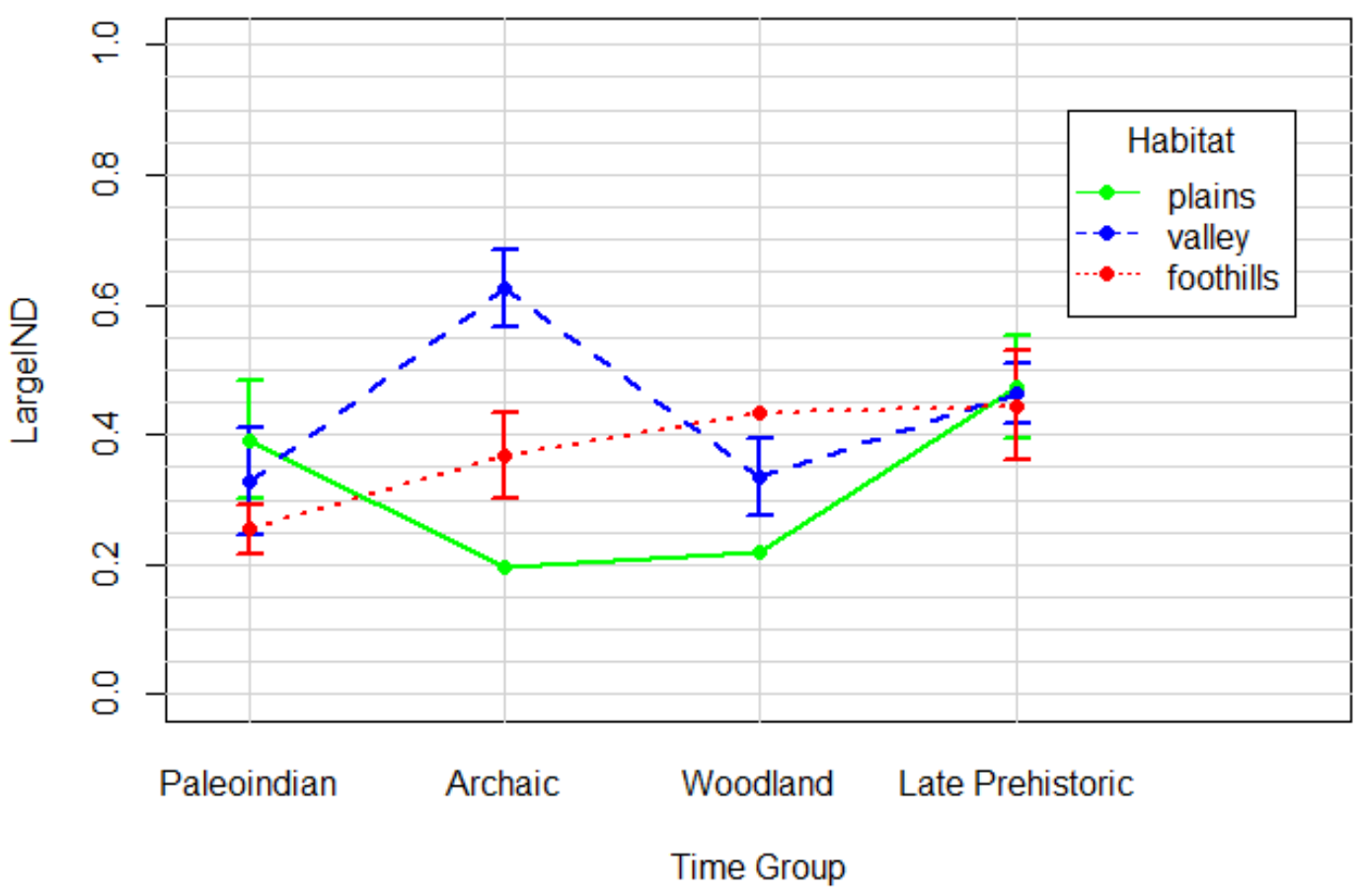

11 Figure 6. Estimates of mean Large Mammal Abundance Index $\left(A I_{l g}\right)$ values with $95 \%$ Confidence 12 Intervals. This plot illustrates estimates across time and habitats (alluvial valleys, plains and rolling hills, 13 and foothills and mountains) for the Paleoindian, Archaic, Woodland, and Late Prehistoric periods. Means 14 and confidence intervals were calculated using a Generalized Linear Model (GLM) using a beta 15 distribution. Estimates without Cls had small sample size (see text). 
As discussed earlier in this paper, the traditional view is that people on the Great Plains

3 (and elsewhere) transitioned from hunting and gathering to farming through a mechanism of

4 increasing resource intensification over time. In this study, we evaluated this hypothesis using a

5 large dataset, finding no support for such a unidirectional intensification over time. Instead, the

6 data show variability in the dietary diversification values, measured using the Margalef Diversity

7 Index and Simpson's Index. Notably, these values do not increase uniformly over time. The

8 results indicate that hunters on the Great Plains and in surrounding areas practiced flexible

9 subsistence strategies. Their foraging and farming behaviors often varied in response to temporal

10 and habitat differences in prey availability (e.g.,Hill 2008; Knell and Hill 2012; Otárola-Castillo

11 2016). This study also sought to compare the Great Plains Paleoindian prey choice patterns we

12 observed in our earlier work to evidence later in time. The data show that the patterns of faunal

13 use found during the Paleoindian period are not consistent over time (Hill 2007a, 2007b, 2008;

14 Hill and Knell 2013; Knell and Hill 2012; Otárola-Castillo 2016).

15 There is a high degree of variability across components. For any period, individual

16 assemblages may show richness and $A I_{l g}$ values that range from 0 to 1 and Margalef Diversity

17 Index values that range between 0 and $~ 3.3$ across habitats. In the broadest sense, both foragers

18 and farmers preyed upon a modest number of species, often with one species numerically

19 dominating the assemblage. The trend of low $A I_{l g}$ values is an indication that large prey like

20 bison were not necessarily the dominant prey in those diets. For the vast majority of time,

21 however, large prey composed approximately $40 \%$ or less of the hunted diet, on average, across

22 all habitats. Figures 7 and 8 directly compare Simpson's evenness and Margalef's richness values

23 and the mean abundance of small, medium, and $A I_{l g}$ values across time, differentiated by habitat. 
1 If one examines the temporal patterns, there are some intriguing changes, although they are not

2 necessarily statistically significant.

3 Despite cooler, more variable climates and lower human population size than in later

4 times, subsistence strategies during the Paleoindian period are not dramatically different from

5 later periods (e.g., Figure 7). As we have shown previously, localities in the plains and rolling

6 hills and in the foothills and mountains have very low average richness and evenness values (Hill

7 2007a, 2007b, 2008; Otárola-Castillo 2016). In terms of our expectations for diversification and

8 specialization, the Paleoindian assemblages in the plains and rolling hills and foothills and

9 mountains reflect a hyper-specialized (low richness/low evenness) subsistence strategy. The A.I.

10 values indicate (Figure 8) that, under this specialized adaptation, hunters likely focused on either

11 large prey or small prey in the plains and rolling hills. In the foothills and mountains, however,

12 the specialization would have been directed toward procuring medium-sized prey.

13 Paleoindian localities in alluvial valleys exhibit a generalist profile. These assemblages

14 possess moderate to high richness values and moderate to high evenness values. In terms of the

15 body size of prey chosen in alluvial settings, the primary focus would have been on small prey

16 mixed with modest contributions from large and medium-sized prey. 

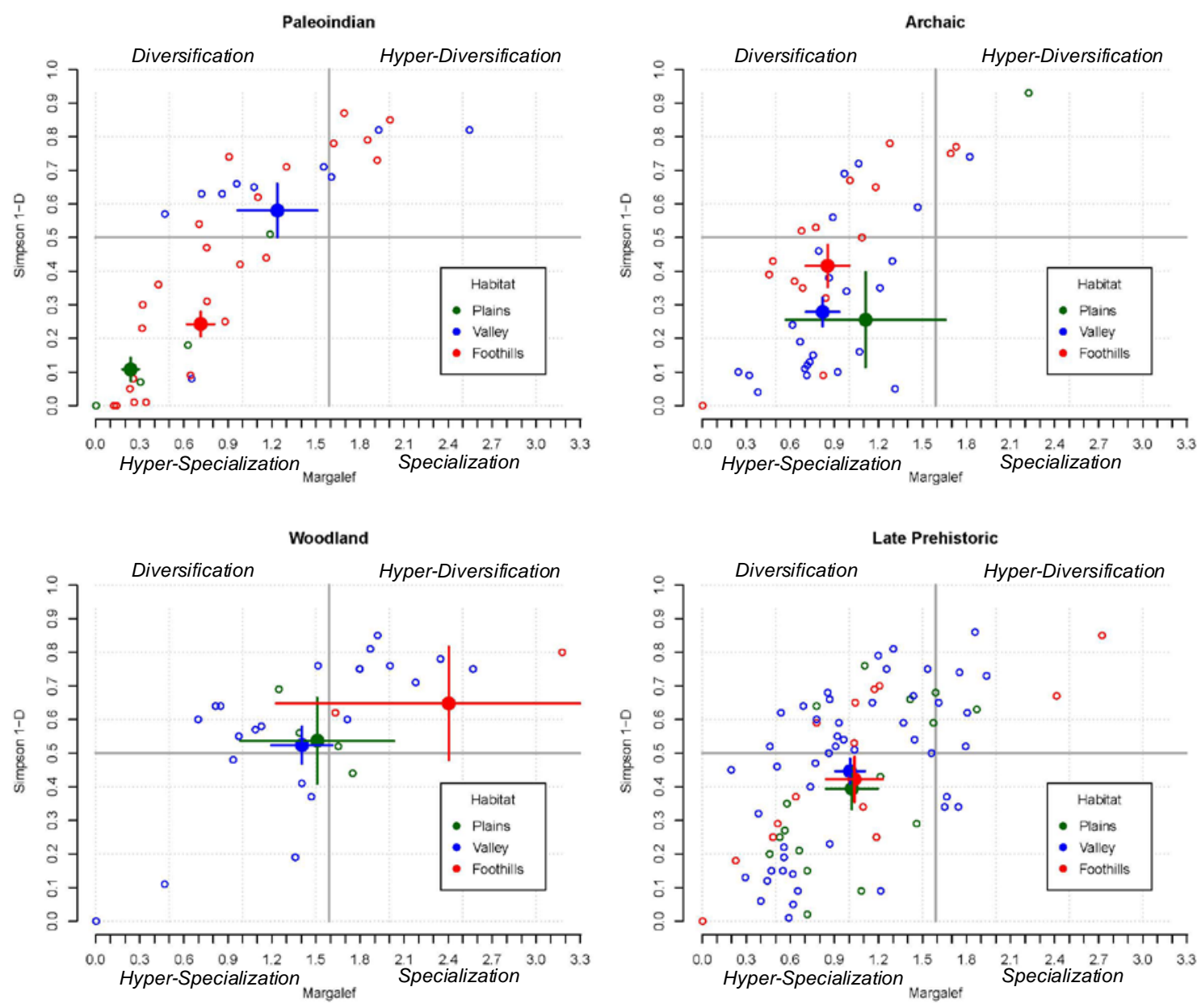

Figure 7. Bivariate plot exhibiting the variability in Margalef's Diversity index $\left(D_{M g}\right)$ and Simpson Index (1-D') values of site components in the three different habitats (alluvial valleys, plains and rolling hills, and foothills and mountains). Each panel separately illustrates the Paleoindian, Archaic, Woodland, and Late Prehistoric periods. Habitat means value with 95\% Confidence Intervals are depicted for each habitat. 


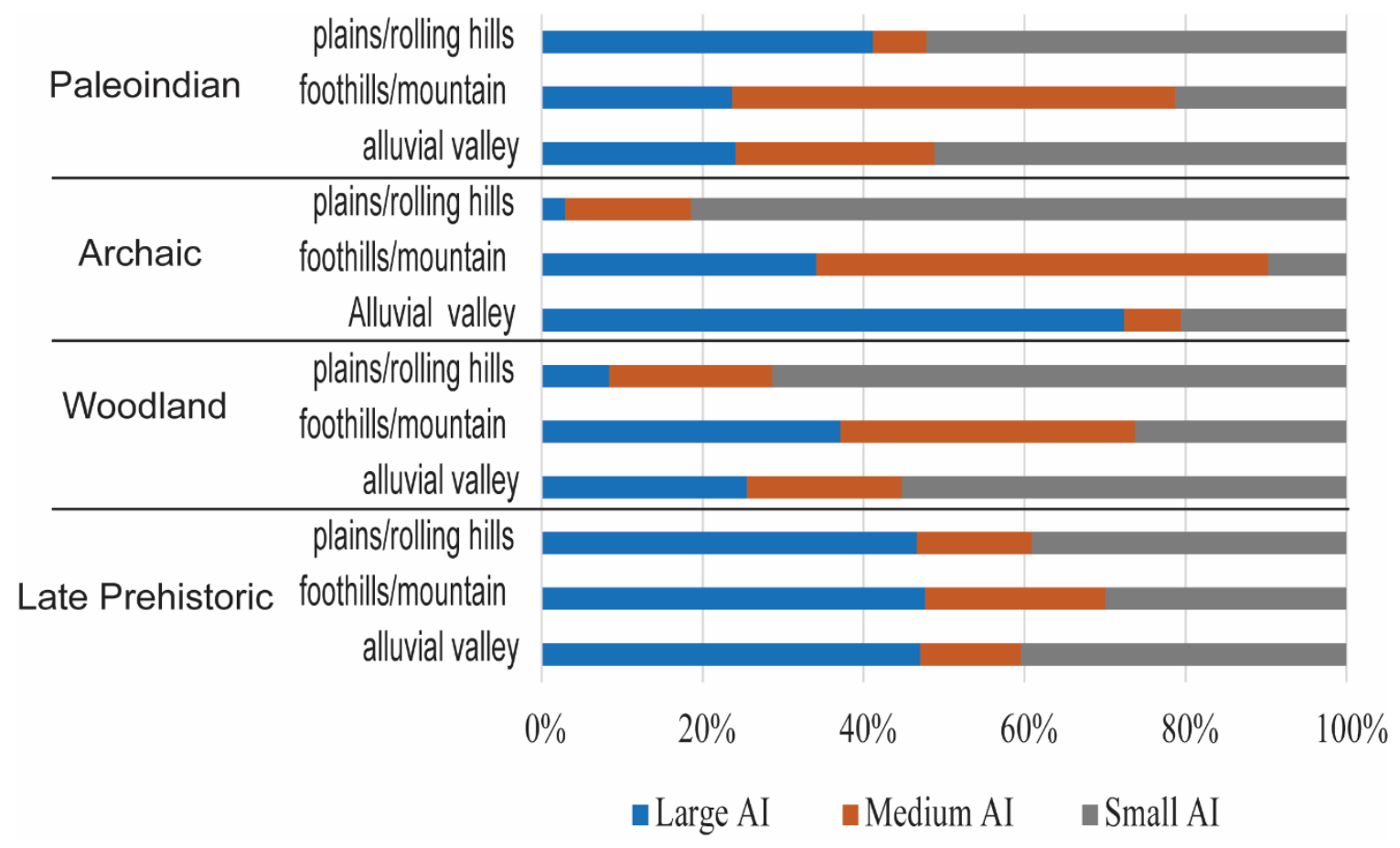

Figure 8. Stacked bar graph illustrating the variability in mean large-bodied Abundance Index $\left(A I_{\mid g}\right)$, medium-bodied Abundance Index $\left(A I_{m e}\right)$, and small-bodied Abundance Index $\left(A I_{s m}\right)$ for three different habitats (alluvial valleys, plains and rolling hills, and foothills and mountains) during the Paleoindian, Archaic, Woodland and Late Prehistoric periods.

The results of this study also challenge the traditional notion that Paleoindian hunters

5 were specialized hunters of big game such as proboscideans and bison (Frison 2001, 2004;

6 Kornfeld, et al. 2010). These foragers indeed had narrow diets, and, for sites in the plains and

7 rolling hills, there is strong evidence of extensive use of large prey. However, in other settings,

8 Paleoindians seem to have specialized in deer, mountain sheep, and small prey, such as rodents

9 and turtles, or enjoyed a more diverse mixture of prey. This duality in subsistence strategies

10 likely represents the environmental constraints under which Paleoindian hunters lived; the

11 proverbial "When in Rome” aphorism seems to be an appropriate moniker for Paleoindian

12 subsistence strategies. Indeed, the ability of Paleoindian foragers to maintain flexible strategies

13 enabled them to shift between degrees of specialization and prey types depending on the setting. 
There is a noticeable paucity of Archaic sites from the plains and rolling hills in our

2 sample. This gap likely reflects the well-documented erosion of upland surfaces and small

3 alluvial valleys of the Great Plains during the middle Holocene (e.g., Bettis III and Mandel 2002;

4 Robertson 2011). Therefore, even though the Archaic sites in the plains and rolling hills show

5 high species richness and evenness, it is difficult to ascertain whether these findings are

6 representative for the Archaic period. We have greater confidence in our results for the foothill

7 and mountain and alluvial valley settings, since the sample sizes are better. In general, our data

8 show that the diets in Archaic plains and foothill sites were richer and slightly more even

9 compared to the Paleoindian period; in alluvial settings, diets were less rich and even compared

10 to earlier times. While a few sites have high Simpson and Margalef values, Archaic hunters seem

11 to have maintained a hyper-specialized diet profile, such as in the very high use of large prey in

12 alluvial valley settings. Surprisingly, the very few plains and rolling hill sites show a dominance

13 of small prey, whereas, in the foothills and mountains, medium-sized prey were dominant.

14 Because of the widespread climatic drying during the middle Holocene, we expected

15 significant declines in the natural abundance of large-bodied fauna. Hill et al. (2008)

16 demonstrated that bison experienced a significant reduction in body size during this period,

17 which is consistent with the high levels of climatic stress and reduced quality of forage.

18 Accordingly, people's low reliance on large-bodied fauna during this time was likely tied to the

19 reduced abundance of large prey in dry grassland habitats. We should note, however, that hunters

20 in the foothills and mountains and alluvial valleys maintained a specialized dietary focus on large

21 and medium prey. We take this as an indication that large and medium prey populations were

22 relatively abundant, at least during specific periods. Alluvial valleys were likely always a

23 common location for human residents and prey to go to get water. Given the increased 
1 temperatures and drought conditions during parts of the Archaic period, these habitats may have

2 acted as refugia, tethering humans and prey to reliable water sources. Mountain springs and

3 surface water sources may have been adequate to support medium-sized prey for humans to hunt.

4 Human population sizes across the Plains and in adjacent regions at this time were likely modest.

5 As such, there is a low probability that humans could have depleted the large and medium-sized

6 prey populations to the extent that foragers would have been forced to significantly broaden their

7 diets.

8 By the Woodland period, the climate ameliorated and became more grass-friendly, for

9 example, with an apparent increase in precipitation levels. These changes could also have caused

10 the size and number of bison herds to increase from middle Holocene levels. Archaeologists'

11 identification of large bison jump sites across the Great Plains supports the notion that bison

12 herds were at least occasionally quite large. However, the Woodland period was also a time of

13 significant technological, social, and adaptive changes in the Great Plains, with the appearance of

14 an incipient horticulture and increased sedentism in alluvial valleys. Developments in ceramic

15 technology served to increase the efficiency and productivity of cooking plant resources. There is

16 evidence of an increase in permanent human presence in the alluvial valleys. We imagine that

17 human populations were growing at unprecedented rates during the Woodland period. However,

18 even in the absence of population growth, decreased mobility during this period would have

19 amplified hunting pressure on large prey populations. At the very least, sedentism likely limited

20 hunters' ability to easily move to where bison were abundant. As a result, lower ranked, but

21 locally abundant smaller prey likely became more attractive to many Woodland hunters.

22 As we expected, all these changes brought about modest reorganizations to the structure

23 of faunal procurement. We must, however, acknowledge the potential effect of sampling 
1 problems. Our most rigorous sample for the Woodland period comes from alluvial valley sites.

2 Overall, all sites move away from the hyper-specialized adaptation seen during the Archaic

3 period toward a more generalized strategy (Figure 7). If the small sample of site components in

4 the foothills and mountains is indeed representative, then some foragers might be classified as

5 hyper-generalists. This strategy requires increases in the richness and evenness of prey selection

6 over their values during the Archaic period. At this time, due to sample sizes, the best inferences

7 come from alluvial settings. If we focus on prey size choice, Woodland hunters seem to have

8 significantly reduced the number of large prey and increased the diversity of small prey

9 compared to the Archaic period.

10 Our results show a dearth of habitat differences in terms of faunal use during the Late

11 Prehistoric period (Figure 7). In effect, dietary diversity, evenness, and reliance on large prey are

12 nearly identical across habitats. Most diets appear to have been hyper-specialized, with a

13 uniform, moderately strong reliance on the use of bison. The data suggest that the inclusion of

14 medium-sized prey in the diet was generally modest, while people were making moderate use of

15 small prey; numerically, this use is only slightly lower than that of large prey (Figure 8).

16 The Late Prehistoric period saw significant increases in population size and sedentism.

17 We expected the high population growth to exert increased hunting pressure and subsequently

18 deplete local bison abundance. The reduction of local game animals is logical, especially in areas

19 where Late Prehistoric people created large residential settlements. However, the relatively high

20 use of bison found during the Late Prehistoric period suggests that people utilized some kind of

21 mechanism to offset declines in availability. We believe that these people implemented changes

22 in procurement strategies and technologies. In the Northwestern Plains, for example, large mass

23 kills and jumps were used during this period. It is likely that in specific places, and at least 
1 seasonally, hunters increased their use of specialized procurement techniques to obtain

2 substantial quantities of bison food products. Of course, jump kills do not characterize bison

3 hunting everywhere on the Plains. However, if logistical, perhaps even modest-sized cooperative

4 hunts were undertaken seasonally, scheduled around people's essential agricultural pursuits. If

5 so, there could have been an increased supply of large prey-animals, even in the face of

6 decreasing local availability.

$7 \quad$ Late Prehistoric people used small prey, such as rodents, fish, and birds, in proportions

8 similar to bigger animals, probably because these prey were attracted to settlements and thus

9 became locally abundant. Unlike bison hunts, which were likely planned and sometimes

10 communal undertakings, various members of society (young and old individuals, as well as men,

11 women, and children) could have participated in the collection of small prey, perhaps even while

12 undertaking other activities, such as tending agricultural fields or collecting wood or water.

\section{CONCLUSION}

14 Popular accounts of indigenous life in the North American Great Plains portray a way of

15 life and diet that was highly contingent on the vast herds of bison that roamed the region.

16 Although romantic to some, this depiction is simplistic and does not acknowledge the

17 multidimensional character of the Plains' indigenous people. Our study examined evidence

18 representing over 13,000 years of this region's cultural history, finding that people exhibited

19 remarkable variation in behaviors and dietary strategies. We conclude that even though the

20 Plains people maintained a way of life associated with bison over time, bison was not the

21 dominant species in their diet. Instead, people responded to marked climatic and habitat

22 variability across space and time by adjusting their hunting strategies accordingly. 
To conduct this study, we developed a useful framework for understanding dietary

2 strategies. We conceptualized a diversification and specialization "space” using indices of

3 richness and evenness in order to characterize the hunting strategies of indigenous people on the

4 Great Plains and quantify changes over time. We have identified four discrete locations in the

5 diversity space - diversification, hyper-diversification, specialization, and hyper-specialization -

6 but do so out of pure convenience. In fact, these locations are not discrete, but comprise a

7 continuous space that, in its current form, is relative to the assemblages in this sample.

8 Nonetheless, we believe that this framework can be useful for comparing and measuring changes

9 in the foraging strategies of small-scale societies over time.

The evolution of hunting strategies and dietary variation that we observed on the Great

11 Plains does not support a model of progressive resource intensification from hunting and

12 gathering to farming. Rather, the data support a model of constant diversification of hunting

13 strategies from the Paleoindian through the Late Prehistoric periods. In this model, hunters on the

14 Plains (and elsewhere) maintained a consistently high diversity of behavioral strategies. This

15 highly flexible and diversified portfolio of dietary strategies enabled the people of the Great

16 Plains to adapt their approaches to procuring food across different habitats and time periods.

\section{ACKNOWLEDGMENTS}

18 We are grateful to various museums and their staff for providing access to the collections and

19 materials used in this study, including the University of Kansas Natural History Museum, the

20 Kansas State Historical Society, the University of Colorado, the Nebraska State Museum, the

21 University of Texas, and the University of Wyoming. MEH is thankful for financial support from

22 the University of Iowa, the Arizona State Museum Thompson Fund (U of Arizona), the Emily

23 W. Haury Education Fund for Archaeology (U of Arizona), and the George C. Frison Institute 
1 Paleoindian Grant (U Wyoming) that facilitated museum visits. MEH thanks Kevin Flaherty for

2 his help in the early stages of data collection and the statistical advice provided by Rhonda R.

3 DeCook, Feiran Jiao, and Barbara Monaco. EOC is grateful to Sarah N. Coon for help with

4 manuscript editing. Partial funding for this project was provided by Purdue University College of

5 Liberal Arts' Exploratory Research in the Social Sciences award and the Margo Katherine Wilke

6 research internship fund. 
Adair, Mary J.

Adair, Mary J. and R. Drass

2006 Plains Plants. Handbook of North American Indians 3:365-374.

2012 Refining Plains Woodland Chronology. Plains Anthropologist 57(223):183-228. 2011 Patterns of Plant Use in the Prehistoric Central and Southern Plains. The Subsistence Economies of Indigenous North American Societies: A Handbook:307-352.

Ahler, Stanley A. and Dennis L. Toom 1995 Archeology of the Medicine Crow Site Complex (39bf2), Buffalo County, South Dakota. State of Illinois.

Anderson, Roger C. 2006 Evolution and Origin of the Central Grassland of North America: Climate, Fire, and Mammalian Grazers. The Journal of the Torrey Botanical Society 133(4):626-647.

Axelrod, Daniel I. 1985 Rise of the Grassland Biome, Central North America. The Botanical Review 51(2):163-201.

Balinsky, Robin L. 1998 Pleistocene to Holocene: Wilson-Leonard Microvertebrate Fauna and Its Paleoenvironmental Significance. In Wilson-Leonard: A 11,000-Year Archaeological Record of Hunter-Gatherers in Central Texas, edited by M. B. Collins, pp. 1515-1542. vol. 5. The University of Texas at Austin.

Bamforth, Douglas B. 2011 Origin Stories, Archaeological Evidence, and Postclovis Paleoindian Bison Hunting on the Great Plains. American Antiquity 76(1):24-40.

\section{Barlow, K. Renee} 2002 Predicting Maize Agriculture among the Fremont: An Economic Comparison of Farming and Foraging in the American Southwest. American Antiquity 67(1):65-88.

Barnosky, Cathy W. 1989 Postglacial Vegetation and Climate in the Northwestern Great Plains of Montana. Quaternary Research 31(1):57-73.

Bayham, Frank E. 
Beaver, Joseph E. and Rebecca M. Dean 2019 Using Euclidean Distance in the Comparative Analysis of Taxonomic Abundance. Journal of Archaeological Science: Reports 25:331-340.

Betancourt, Julio L., Kate A. Rylander, Cristina Peñalba and Janet L. McVickar 2001 Late Quaternary Vegetation History of Rough Canyon, South-Central New Mexico, USA. Palaeogeography, Palaeoclimatology, Palaeoecology 165(1-2):71-95.

Bettinger, Robert L. and Mark N. Grote 2016 Marginal Value Theorem, Patch Choice, and Human Foraging Response in Varying Environments. Journal of Anthropological Archaeology 42:79-87.

Bettinger, Robert L., Bruce Winterhalder and Richard McElreath 2006 A Simple Model of Technological Intensification. Journal of Archaeological Science 33(4):538-545.

Bettis III, E. Arthur and Rolfe D. Mandel

2002 The Effects of Temporal and Spatial Patterns of Holocene Erosion and Alluviation on the Archaeological Record of the Central and Eastern Great Plains, USA. Geoarchaeology: An International Journal 17(2):141-154.

Betts, Matthew W. and T. Max Friesen 2004 Quantifying Hunter-Gatherer Intensification: A Zooarchaeological Case Study from Arctic Canada. Journal of Anthropological Archaeology 23(4):357-384.

Binford, Lewis R.

1980 Willow Smoke and Dogs’ Tails: Hunter-Gatherer Settlement Systems and Archaeological Site Formation. American Antiquity 45(1):4-20.

2001 Constructing Frames of Reference: An Analytical Method for Archeological Theory Using Hunter-Gatherer and Environmental Data Sets. Berkeley: University of California Press.

Bird, Douglas W. and James F. O’Connell 2006 Behavioral Ecology and Archaeology. Journal of Archaeological Research 14(2):143-188.

Blackmar, Jeannette M. and Jack L. Hofman 2006 The Paleoarchaic of Kansas. Kansas Archaeology:10-27.

Bleed, Peter

1986 The Optimal Design of Hunting Weapons: Maintainability or Reliability. American Antiquity 51(4):737-747. 
42

43

44

45

46
Boivin, Nicole L., Melinda A. Zeder, Dorian Q. Fuller, Alison Crowther, Greger Larson, Jon M. Erlandson, Tim Denham and Michael D. Petraglia 2016 Ecological Consequences of Human Niche Construction: Examining Long-Term Anthropogenic Shaping of Global Species Distributions. Proceedings of the National Academy of Sciences 113(23):6388-6396.

Boserup, Ester 1965 The Conditions of Agricultural Growth. The Economics of Agrarian Change under Population Pressure. Aldine, Chicago.

Bousman, C. Britt 1998 Paleoenvironmental Change in Central Texas: The Palynological Evidence. Plains Anthropologist 43(164):201-219.

Bozell, John R., Carl R. Falk and Eileen Johnson 2011 Native American Use of Animals on the North American Great Plains. In The Subsistence Economies of Indigenous North American Societies: A Handbook, edited by B. D. Smith, pp. 353-385. Smithsonian Institution Scholarly Press, Washington, D.C.

Brain, C.K.

1981 The Hunters or the Hunted? University of Chicago Press.

Bright, Jason, Andrew Ugan and Lori Hunsaker 2002 The Effect of Handling Time on Subsistence Technology. World Archaeology 34(1):164-181.

Brookfield, Harold C. 1972 Intensification and Disintensification in Pacific Agriculture: A Theoretical Approach. Pacific Viewpoint 13(1):30-48.

Broughton, Jack M.

1994a Declines in Mammalian Foraging Efficiency During the Late Holocene, San Francisco Bay, California. Journal of Anthropological Archaeology 13:371-371.

1994b Late Holocene Resource Intensification in the Sacramento Valley, California: The Vertebrate Evidence. Journal of Archaeological Science 21(4):501-514.

1997 Widening Diet Breadth, Declining Foraging Efficiency, and Prehistoric Harvest Pressure: Ichthyofaunal Evidence from the Emeryville Shellmound, California. Antiquity 71(274):845-862.

1999 Resource Depression and Intensification During the Late Holocene, San Francisco Bay: Evidence from the Emeryville Shellmound Vertebrate Fauna 32. University of California Press. 
2002 Prey Spatial Structure and Behavior Affect Archaeological Tests of Optimal Foraging Models: Examples from the Emeryville Shellmound Vertebrate Fauna. World Archaeology 34(1):60-83.

Broughton, Jack M., Michael D. Cannon and Eric J. Bartelink 2010 Evolutionary Ecology, Resource Depression, and Niche Construction Theory: Applications to Central California Hunter-Gatherers and Mimbres-Mogollon Agriculturalists. Journal of Archaeological Method and Theory 17(4):371-421.

Broughton, Jack M. and Elic M. Weitzel 2018 Population Reconstructions for Humans and Megafauna Suggest Mixed Causes for North American Pleistocene Extinctions. Nature Communications 9(1):1-12.

Butler, Virginia L. and Sarah K. Campbell 2004 Resource Intensification and Resource Depression in the Pacific Northwest of North America: A Zooarchaeological Review. Journal of World Prehistory 18(4):327405.

Byerly, Ryan M., Judith R. Cooper, David J. Meltzer, Matthew E. Hill and Jason M. LaBelle 2005 On Bonfire Shelter (Texas) as a Paleoindian Bison Jump: An Assessment Using Gis and Zooarchaeology. American Antiquity 70(4):595-629.

Byers, D. A. and J. M. Broughton 2004 Holocene Environmental Change, Artiodactyl Abundances, and Human Hunting Strategies in the Great Basin. American Antiquity 69(2):235-255.

Cannon, Michael D. 2001 Large Mammal Resource Depression and Agricultural Intensification: An Empirical Test in the Mimbres Valley, New Mexico.

Cannon, Michael D. and David J. Meltzer 2004 Early Paleoindian Foraging: Examining the Faunal Evidence for Large Mammal Specialization and Regional Variability in Prey Choice. Quaternary Science Reviews 23(18-19):1955-1987.

2008 Explaining Variability in Early Paleoindian Foraging. Quaternary International 191(1):5-17.

Clark, James S., Eric C. Grimm, Joseph J. Donovan, Sherilyn C. Fritz, Daniel R. Engstrom and James E. Almendinger

2002 Drought Cycles and Landscape Responses to Past Aridity on Prairies of the Northern Great Plains, USA. Ecology 83(3):595-601.

Clifford, Harold T., William Stephenson, H. Clifford and W. Stephenson 1975 An Introduction to Numerical Classification 240. Academic Press New York. 
Coupland, Gary, Kathlyn Stewart and Katherine Patton 2010 Do You Never Get Tired of Salmon? Evidence for Extreme Salmon Specialization at Prince Rupert Harbour, British Columbia. Journal of Anthropological Archaeology 29(2):189-207.

Coupland, Robert T. 1992 Overview of the Grasslands of North America. Ecosystems of the World 8:147149.

Cribari-Neto, Francisco and Achim Zeileis 2010 Beta Regression in R. Journal of Statistical Software 34(2):1-24. URL http://www.jstatsoft.org/v34/i02/.

Dansgaard, Will, Sigfus J. Johnsen, Jesper Møller and Chester C. Langway 1969 One Thousand Centuries of Climatic Record from Camp Century on the Greenland Ice Sheet. Science 166(3903):377-380.

Dean, Rebecca M. 2007 Hunting Intensification and the Hohokam “Collapse”. Journal of Anthropological Archaeology 26(1):109-132.

2017 Fauna and the Emergence of Intensive Agricultural Economies in the United States Southwest. In The Oxford Handbook of Zooarchaeology.

Dean, Walter E. and Antje Schwalb 2000 Holocene Environmental and Climatic Change in the Northern Great Plains as Recorded in the Geochemistry of Sediments in Pickerel Lake, South Dakota. Quaternary International 67(1):5-20.

DeAngelis, Joseph A. and R. Lee Lyman 2018 Evaluation of the Early Paleo-Indian Zooarchaeological Record as Evidence of Diet Breadth. Archaeological and Anthropological Sciences 10(3):555-570.

Dyck, Ian and Richard E. Morlan 2001 Hunting and Gathering Tradition: Canadian Plains. Handbook of North American Indians 13(1):115-130.

Earle, Timothy K. 1980 A Model of Subsistence Change. In Modeling Change in Prehistoric Subsistence Economies, edited by T. K. Earle and A. L. Christenson, pp. 1-29. Academic Press, New York.

Ellyson, Laura J., Lisa Nagaoka and Steve Wolverton 2019 Animal Resource Use Related to Socioenvironmental Change among Mesa Verde Farmers. Journal of Anthropological Research 75(3):361-392. 
44

Fagan, Brian M. 2018 Ancient North America: The Archaeology of a Continent. 5th ed. Thames \& Hudson, New York.

Faith, J. Tyler and Andrew Du 2018 The Measurement of Taxonomic Evenness in Zooarchaeology. Archaeological and Anthropological Sciences 10(6):1419-1428.

Fladmark, Knut R. 1975 A Paleoecological Model for Northwest Coast Prehistory. National Museum of Man, Mercury Series. Archaeological Survey of Canada Paper 43, Ottawa. 1982 an Introduction to the Prehistory of British Columbia. Canadian Journal of Archaeology 3:131-144.

Flannery, Kent V. 1968 Archaeological Systems Theory and Early Mesoamerica. Anthropological Archaeology in the Americas 67:87.

1972 The Cultural Evolution of Civilizations. Annual Review of Ecology and Systematics 3(1):399-426.

Forbis, Richard G. 1982 One View of Plains Archaeology in Canada: The Past Decade. Canadian Journal of Archaeology (6):157-166.

Forman, Steven L., Robert Oglesby and Robert S. Webb 2001 Temporal and Spatial Patterns of Holocene Dune Activity on the Great Plains of North America: Megadroughts and Climate Links. Global and Planetary Change 29(12):1-29.

Frank, Douglas A., Michelle M. Kuns and Daniel R. Guido 2002 Consumer Control of Grassland Plant Production. Ecology 83(3):602-606.

Frank, Douglas A., S. J. McNaughton and B. F. Tracy 1998 The Ecology of the Earth's Grazing Ecosystems. Bioscience 48(7):513-521.

Frank, Douglas A. and Samuel J. Mcnaughton 1993 Evidence for the Promotion of Aboveground Grassland Production by Native Large Herbivores in Yellowstone-National-Park. Oecologia 96(2):157-161.

Fredlund, Glen G., C. Britt Bousman and Douglas K. Boyd 1998 The Holocene Phytolith Record from Morgan Playa in the Rolling Plains of Texas. Plains Anthropologist 43(164):187-200.

Frison, George C. 
44 45

1970 The Kobold Site, 24bh406: A Post-Althithermal Record of Buffalo-Jumping for the Northwestern Plains. Plains Anthropologist 15(47):1-35.

1998a The Northwestern and Northern Plains. . In Archaeology on the Great Plains, edited by W. R. Wood, pp. 140-172. University Press of Kansas, Lawrence, KS.

1998b Paleoindian Large Mammal Hunters on the Plains of North America. Proceedings of the National Academy of Sciences 95(24):14576-14583.

2001 Hunting and Gathering Tradition: Northwestern and Central Plains. Plains 13:131-145.

2004 Survival by Hunting: Prehistoric Human Predators and Animal Prey. University of California Press.

Grayson, Donald K. and David J. Meltzer 2002 Clovis Hunting and Large Mammal Extinction: A Critical Review of the Evidence. Journal of World Prehistory 16(4):313-359.

Gremillion, Kristen J. 2004 Seed Processing and the Origins of Food Production in Eastern North America. American Antiquity 69(2):215-233.

Gremillion, Kristen J., Loukas Barton and Dolores R. Piperno 2014 Particularism and the Retreat from Theory in the Archaeology of Agricultural Origins. Proceedings of the National Academy of Sciences 111(17):6171-6177.

Gremillion, Kristen J. and Dolores R. Piperno 2009 Human Behavioral Ecology, Phenotypic (Developmental) Plasticity, and Agricultural Origins: Insights from the Emerging Evolutionary Synthesis. Current Anthropology 50(5):615-619.

Halfen, Alan F. and William C. Johnson 2013 A Review of Great Plains Dune Field Chronologies. Aeolian Research 10:135160.

Haury, Cherie 2005 Analysis of Fauna from the Rustad Site. Plains Anthropologist 50(196):91-133.

Haynes, Gary and Jarod Hutson, M. 2014 Clovis-Era Subsistence: Regional Variability, Continental Patterning. In Paleoamerican Odyssey, edited by K. E. Graf, C. V. Ketron and M. R. Waters, pp. 293309. Texas A\&M University Press.

Hill, Matthew E. 
Hofman, Jack L. 1994 Paleoindian Aggregations on the Great Plains. Journal of Anthropological Archaeology 13(4):341-370.

Holliday, Vance T. 1995 Stratigraphy and Paleoenvironments of Late Quaternary Valley Fills on the Southern High Plains. Geological Society of America, Boulder, Colorado.

Johnson, A.M. and A.W. Johnson 1998 The Plains Woodland. In Archaeology of the Great Plains, edited by W. R. Wood, pp. 201-234. University of Kansas Press, Lawrence.

Johnson, Eileen 1986 Late Pleistocene and Early Holocene Vertebrates and Paleoenvironments on the Southern High Plains, USA. Geographie Physique et Quaternaire 40(3):249-261.

1987 Lubbock Lake: Late Quaternary Studies on the Southern High Plains. Texas A\&M University Press.

Kay, Marvin 1998 The Central and Southern Plains Archaic. Archaeology on the Great Plains:173200. 
Kehoe, Thomas F.

1973 The Gull Lake Site: A Prehistoric Bison Drive Site in Southwestern

Saskatchewan. Milwaukee Public Museum.

Kelly, Robert L. and Lawrence C. Todd 1988 Coming into the Country: Early Paleoindian Hunting and Mobility. American Antiquity 53(2):231-244.

Klein, Richard G.

1976 The Mammalian Fauna of the Klasies River Mouth Sites, Southern Cape Province, South Africa. The South African Archaeological Bulletin 31(123/124):75-98.

Knell, Edward J. 2007 The Organization of Late Paleoindian Cody Complex Land-Use on the North American Great Plains. Thesis/dissertation (deg); Manuscript (mss), Department of Anthropology, Washington State University.

Knell, Edward J. and Matthew E. Hill 2012 Linking Bones and Stones: Regional Variation in Late Paleoindian Cody Complex Land Use and Foraging Strategies. American Antiquity 77(1):40-70.

Kornfeld, Marcel 1997 Affluent Foragers of the Western Black Hills: A Settlement and Subsistence Model. In Changing Perspectives of the Archaic on the Northwest Plains and Rocky Mountains, edited by M. L. Larson and J. E. Francis, pp. 56-84. University of South Dakota Press, Vermillion.

2007 Are Paleoindians of the Great Plains and Rockies Subsistence Specialists? In Foragers of the Terminal Pleistocene, edited by R. B. Walker and B. N. Driskell, pp. 32-58. University of Nebraska Press, Lincoln.

Kornfeld, Marcel, George C. Frison and Mary L. Larson 2010 Prehistoric Hunter-Gatherers of the High Plains and Rockies. 3rd ed. Left Coast Press, Walnut Creek, California.

Kornfeld, Marcel and Mary L. Larson 2008 Bonebeds and Other Myths: Paleoindian to Archaic Transition on North American Great Plains and Rocky Mountains. Quaternary International 191(1):18-33.

Kornfeld, Marcel, Mary L. Larson, Craig Arnold, Adam Wiewel, Mike Toft and Dennis Stanford 2007 The Nelson Site, a Cody Occupation in Northeastern Colorado. Plains Anthropologist 52(203):257-278.

Küchler, August W. 1965 Potential Natural Vegetation of the Conterminous United States. Soil Science 99(5):356. 
Kuhn, Steven L.

1994 A Formal Approach to the Design and Assembly of Mobile Toolkits. American Antiquity 59(3):426-442.

Lauenroth, William K., Ingrid C. Burke and Myron P. Gutmann 1999 The Structure and Function of Ecosystems in the Central North American Grassland Region. Great Plains Research:223-259.

Leach, Helen M 1999 Intensification in the Pacific: A Critique of the Archaeological Criteria and Their Application. Current Anthropology 40(3):311-340.

Lehmer, Donald J. 1971 Introduction to Middle Missouri Archeology. Anthropological Papers No. 1, National Park Service, Washington, D.C.

Lenth, Russell 2020 Emmeans: Estimated Marginal Means, Aka Least-Squares Means. R Package Version 1.4.6. https://Cran.R-Project.Org/Package=Emmeans.

Levins, Richard 1968 Evolution in Changing Environments: Some Theoretical Explorations. Princeton University Press.

Liberty, Margot and W. Raymond Wood 1980 Anthropology on the Great Plains. University of Nebraska Press, Lincoln.

Lobdell, John E. 1973 The Scoggin Site: An Early Middle Period Bison Kill. Wyoming Archaeologist 16(3).

Lyman, R. Lee 1989 Seal and Sea Lion Hunting: A Zooarchaeological Study from the Southern Northwest Coast of North America. Journal of Anthropological Archaeology 8(1):68-99. 1991 Subsistence Change and Pinniped Hunting. In Human Predators and Prey Mortality, edited by M. C. Stiner, pp. 187-199. Westview Press, Boulder, Colorado.

Mack, Richard N. and John N. Thompson 1982 Evolution in Steppe with Few Large, Hooved Mammals. The American Naturalist 119(6):757-773.

42

43 2004 Measuring Biological Diversity. Blackwell, Malden, Massachusetts 
44

45 Mulloy, William

Malthus, Thomas

1798 An Essay on the Principle of Population. Reeves and Turner, St. Paul's ChurchYard, London.

Matson, Richard G. 1983 Intensification and the Development of Cultural Complexity: The Northwest Versus the Northeast Coast. In The Evolution of Maritime Cultures on the Northeast and Northwest Coasts of America, edited by R. J. Nash, pp. 125-148.

Matson, Richard G. and Gary Coupland (editors) 1995 The Prehistory of the Northwest Coast. Academic Press, San Diego.

McNaughton, Samuel J. 1984 Grazing Lawns: Animals in Herds, Plant Form, and Coevolution. The American Naturalist 124(6):863-886.

Meltzer, David J. 1999 Human Responses to Middle Holocene (Altithermal) Climates on the North American Great Plains. Quaternary Research 52(3):404-416.

2015 Pleistocene Overkill and North American Mammalian Extinctions. Annual Review of Anthropology 44:33-53.

Metcalfe, Duncan and K. Renee Barlow 1992 A Model for Exploring the Optimal Trade-Off between Field Processing and Transport. American Anthropologist 94(2):340-356.

Miller, Shane D. 2018 From Colonization to Domestication: Population, Environment, and the Origins of Agriculture in Eastern North America. University of Utah Press.

Morgan, Christopher 2015 Is It Intensification Yet? Current Archaeological Perspectives on the Evolution of Hunter-Gatherer Economies. Journal of Archaeological Research 23(2):163-213.

Morrison, Kathleen D. 1994 The Intensification of Production: Archaeological Approaches. Journal of Archaeological Method and Theory 1(2):111-159.

Moss, Madonna L. 2012 Understanding Variability in Northwest Coast Faunal Assemblages: Beyond Economic Intensification and Cultural Complexity. The Journal of Island and Coastal Archaeology 7(1):1-22. 
1954 The Mckean Site in Northeastern Wyoming. Southwestern Journal of Anthropology 10(4):432-460.

Munro, Natalie D. 2004 Small Game Indicators of Human Foraging Efficiency and Early Herd Management at the Transition to Agriculture in South-West Asia. Proceedings of the Petits animaux et sociétés humaines (du complément alimentaire aux ressources utilitaires):515-531.

2009 Epipaleolithic Subsistence Intensification in the Southern Levant: The Faunal Evidence. In The Evolution of Hominin Diets, pp. 141-155. Springer.

Munro, Natalie D., Guy Bar-Oz, Jacqueline S. Meier, Lidar Sapir-Hen, Mary C. Stiner and Reuven Yeshurun 2018 The Emergence of Animal Management in the Southern Levant. Scientific Reports 8(1):1-11.

Nagaoka, Lisa 2002 The Effects of Resource Depression on Foraging Efficient, Diet Breadth, and Patch Use in Southern

New Zealand. Journal of Anthropological Archaeology 21:419-442.

Neusius, Sarah W. and G. Timothy Gross 2013 Seeking Our Past: An Introduction to North American Archaeology. Oxford University Press, New York City.

Oswalt, Wendell H. 1976 An Anthropological Analysis of Food-Getting Technology. Wiley, Hoboken, New Jersey.

Otárola-Castillo, Erik R. 2016 A Spatio-Temporal Model of Hunter-Gatherer Foraging Ecology across the North American Great Plains Throughout the Paleoindian Period: Development of Biological Theory and Statistical Methods to Link Human Evolutionary Biology, Ecology, and the Archaeological Record. Ph.D. dissertation, Interdepartmental Doctoral Program in Anthropological Sciences, Stony Brook University, Stony Brook.

\section{$\mathrm{R}$ Core Team}

2020 R: A Language and Environment for Statistical Computing. R Foundation for Statistical Computing, Vienna, Austria.

Reid, Kenneth C.

1983 The Nebo Hill Phase: Late Archaic Prehistory in the Lower Missouri Valley. In Archaic Hunter-Gatherers in the American Midwest, edited by J. L. Phillips and J. A. Brown, pp. 11-39. Academic Press, New York. 
Reitz, Elizabeth J. and Elizabeth S. Wing

1999 Zooarchaeology. Cambridge University Press.

Robertson, Elizabeth C.

2011 Reassessing Hypsithermal Human-Environment Interaction on the Northern Plains. Geological Society, London, Special Publications 352(1):181-194.

Schmits, Larry J. 1978 The Coffey Site: Environment and Cultural Adaptation at a Prairie Plains Archaic Site. Midcontinental Journal of Archaeology 3.

Sellet, Frederic 1999 A Dynamic View of Paleoindian Assemblages at the Hell Gap Site, Wyoming: Reconstructing Lithic Technological Systems. Ph.D. dissertation, Department of Anthropology, Southern Methodist University, Dallas.

Semken Jr, Holmes A. and Carl R. Falk 1987 Late Pleistocene/Holocene Mammalian Faunas and Environmental Changes on the Northern Plains of the United States. Late Quaternary Mammalian Biogeography and Environments of the Great Plains and Prairies:176-313.

Shuman, Bryan N. and Jeremiah Marsicek 2016 The Structure of Holocene Climate Change in Mid-Latitude North America. Quaternary Science Reviews 141:38-51.

Simpson, Edward H.

1949 Measurement of Diversity. Nature 163(4148):688-688.

Smith, Bruce D. 2011 A Cultural Niche Construction Theory of Initial Domestication. Biological Theory 6(3):260-271.

2015 A Comparison of Niche Construction Theory and Diet Breadth Models as Explanatory Frameworks for the Initial Domestication of Plants and Animals. Journal of Archaeological Research 23(3):215-262.

Smith, Eric A. 2004 Why Do Good Hunters Have Higher Reproductive Success? Human Nature 15(4):343-364.

Stiner, Mary C. 2001 Thirty Years on the "Broad Spectrum Revolution" and Paleolithic Demography. Proceedings of the National Academy of Sciences 98(13):6993-6996.

Stiner, Mary C. and Natalie D. Munro 
42

43

44

45

46

2002 Approaches to Prehistoric Diet Breadth, Demography, and Prey Ranking Systems in Time and Space. Journal of Archaeological Method and Theory 9(2):181-214.

Stiner, Mary C., Natalie D. Munro, Todd A. Surovell, Guy Bar-Oz, Tamar Dayan, Nuno Ferreira Bicho, Amilcare Bietti, Jean-Philip Brugal, Eudald Carbonell and Kent V. Flannery 2000 The Tortoise and the Hare: Small-Game Use, the Broad-Spectrum Revolution, and Paleolithic Demography. Current Anthropology 41(1):39-79.

Stiner, Mary C., Natalie D. Munro, Todd A. Surovell, Eitan Tchernov and Ofer Bar-Yosef 1999 Paleolithic Population Growth Pulses Evidenced by Small Animal Exploitation. Science 283(5399):190-194.

Surovell, Todd A. and Nicole M. Waguespack 2008 How Many Elephant Kills Are 14?: Clovis Mammoth and Mastodon Kills in Context. Quaternary International 191(1):82-97.

2009 Human Prey Choice in the Late Pleistocene and Its Relation to Megafaunal Extinctions. In American Megafaunal Extinctions at the End of the Pleistocene, pp. 77-105. Springer, New York.

Szuter, Christine R. and Frank E. Bayham 1989 Sedentism and Prehistoric Animal Procurement among Desert Horticulturalists of the North American Southwest. In Farmers as Hunters: The Implications of Sedentism, edited by S. Kent, pp. 80-95.

Theler, James L. 2003 Paleoenvironmental Interpretation from Burnham Site Gastropods: 1989 Results. In The Burnham Site in Northwestern Oklahoma: Glimpses Beyond Clovis?, edited by D. G. Wyckoff, J. L. Theler and B. G. Carter, pp. 169-189. vol. 9. Sam Noble Oklahoma Museum of Natural History, University of Oklahoma/Oklahoma Anthropological Society, Norman, Oklahoma.

Thies, Randall M. (editor) 1990 The Archeology of the Stigenwalt Site, 14lt351. Contract Archaeology Series No. 7, Kansas State Historical Society, Topeka.

Thurston, Tina L and Christopher T Fisher 2007 Seeking a Richer Harvest: The Archaeology of Subsistence Intensification, Innovation, and Change. In Seeking a Richer Harvest: The Archaeology of Subsistence Intensification, Innovation, and Change, edited by T. L. Thurston and C. T. Fisher. Springer, Boston.

Tieszen, Larry L., Bradley C. Reed, Norman B. Bliss, Bruce K. Wylie and Donovan D. DeJong 1997 Ndvi, C3 and C4 Production, and Distributions in Great Plains Grassland Land Cover Classes. Ecological Applications 7(1):59-78. 


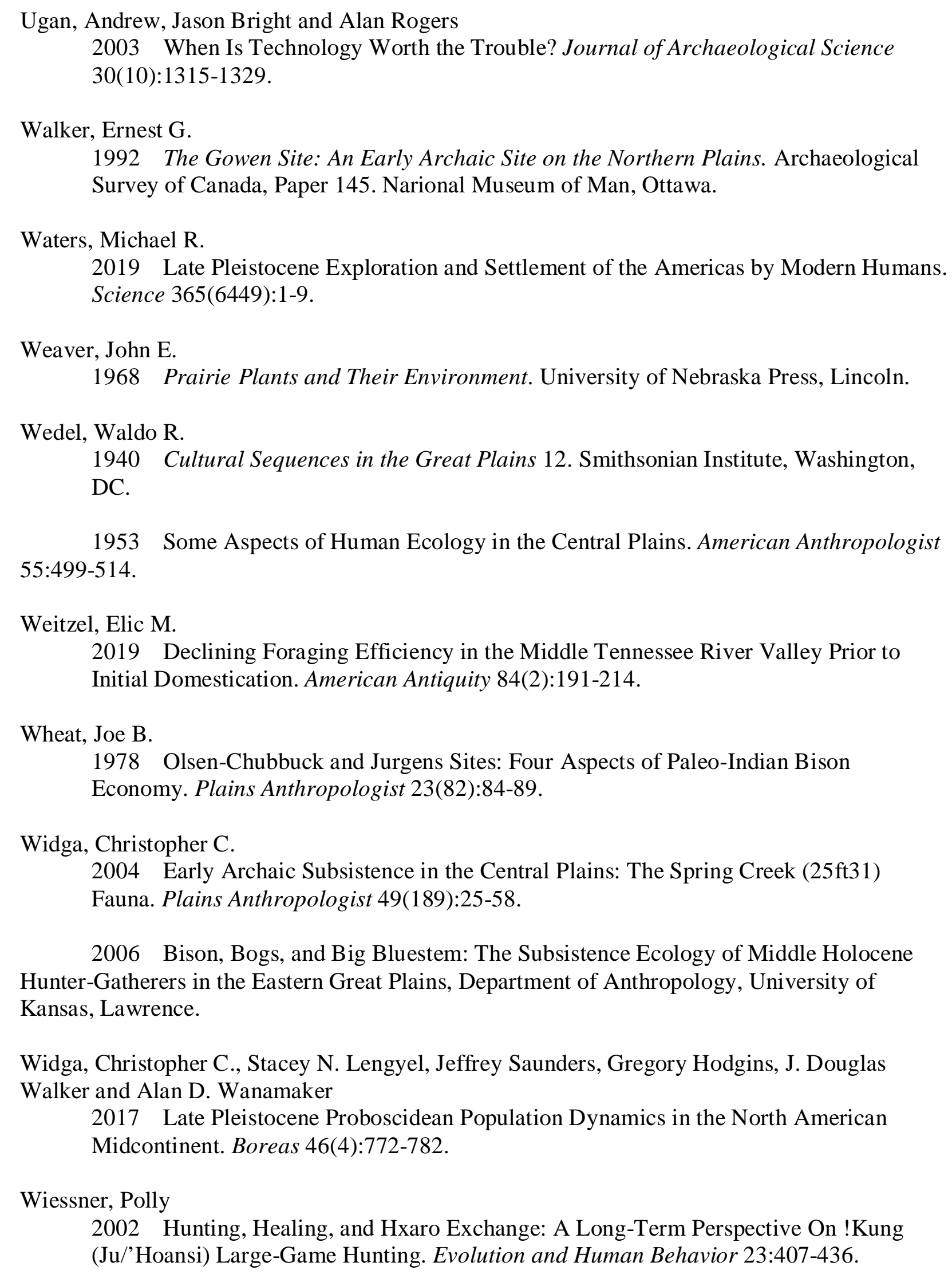




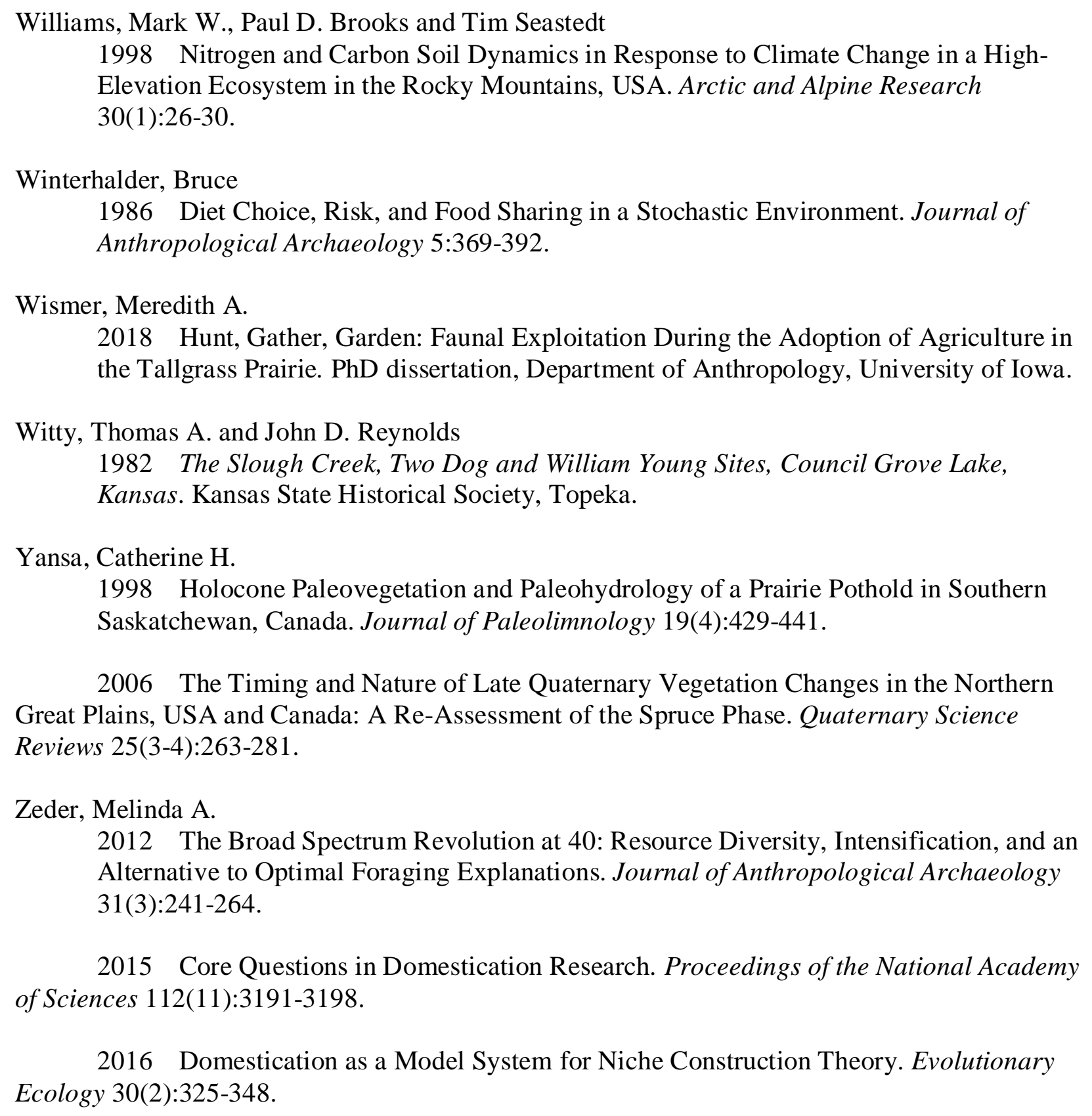

37

38 
Table 1. Site frequency by time period and habitat setting

\begin{tabular}{lcccc}
\hline Setting & Paleoindian & Archaic & Woodland & Late Prehistoric \\
\hline Alluvial Valleys & 11 & 25 & 22 & 48 \\
Foothills/Mountains & 29 & 20 & 2 & 14 \\
Plains/Rolling Hills & 11 & 2 & 4 & 16 \\
\hline
\end{tabular}

$\mathrm{X}=42.09, \mathrm{df}=6, \mathrm{p}<.0001$, Cramer $\mathrm{V}=.321$

Table 2. Mean Margalef $\mathrm{D}_{\mathrm{mg}}$ values (and standard errors) by time period and habitat setting, calculated using a Generalized Linear Model with Gamma function

\begin{tabular}{lcccc}
\hline Setting & Paleoindian & Archaic & Woodland & Late Prehistoric \\
\hline Alluvial Valleys & $1.24(.28)$ & $.82(.12)$ & $1.41(.21)$ & $1.01(.10)$ \\
Foothills/Mountains & $.70(.08)$ & $.83(.13)$ & $2.41(1.20)$ & $1.04(.20)$ \\
Plains/Rolling Hills & $.24(.06)$ & $1.11(.56)$ & $1.51(.53)$ & $1.02(.18)$ \\
\hline
\end{tabular}

Table 3. Mean Simpon's Index 1-D' values (and standard errors) by time period and habitat setting, calculated using Beta Regression

\begin{tabular}{lcccc}
\hline Setting & Paleoindian & Archaic & Woodland & Late Prehistoric \\
\hline Alluvial Valleys & $.58(.08)$ & $.28(.04)$ & $.52(.05)$ & $.42(.07)$ \\
Foothills/Mountains & $.24(.04)$ & $.42(.06)$ & $.65(.17)$ & $.45(.04)$ \\
Plains/Rolling Hills & $.11(.03)$ & $.26(.14)$ & $.54(.13)$ & $.40(.06)$ \\
\hline
\end{tabular}

Table 4. Mean Large-Bodied Abundance Index (AI) values (and standard errors) by time period and habitat setting, calculated using Beta Regression

\begin{tabular}{lcccc}
\hline Setting & Paleoindian & Archaic & Woodland & Late Prehistoric \\
\hline Alluvial Valleys & $.33(.08)$ & $.63(.06)$ & $.34(.06)$ & $.47(.05)$ \\
Foothills/Mountains & $.26(.04)$ & $.37(.07)$ & $.43(.22)$ & $.44(.08)$ \\
Plains/Rolling Hills & $.39(.09)$ & $.20(.13)$ & $.22(.10)$ & $.47(.08)$ \\
\hline
\end{tabular}




\begin{tabular}{|c|c|c|c|c|c|c|c|c|c|c|}
\hline \multicolumn{11}{|c|}{ Appendix 1. Summary Information for Archaeological Sites used in this study. } \\
\hline SITE & Component & Habitat & $\begin{array}{l}\text { Time } \\
\text { Group }\end{array}$ & $\begin{array}{l}\text { Total } \\
\text { NISP }\end{array}$ & Species Count & $\begin{array}{c}\text { Margalef } \\
\text { Dmg }\end{array}$ & Simpon's 1-D' & $\begin{array}{l}\text { Large } \\
\text { AI }\end{array}$ & $\begin{array}{c}\text { Medium } \\
\text { AI }\end{array}$ & $\begin{array}{c}\text { Small } \\
\text { AI }\end{array}$ \\
\hline 13ML175 & $\begin{array}{l}1995 \\
\text { excavations }\end{array}$ & AV & LP & 6,482 & 10 & 1.22 & 0.09 & 0.00 & 0.01 & 0.99 \\
\hline 14CO01 & site & AV & LP & 6,353 & 4 & 0.54 & 0.62 & 0.49 & 0.11 & 0.40 \\
\hline 14CO03 & site & AV & LP & 11,575 & 6 & 0.77 & 0.47 & 0.64 & 0.08 & 0.28 \\
\hline 14CO1509 & site & AV & LP & 984 & 5 & 0.59 & 0.01 & 0.99 & 0.00 & 0.00 \\
\hline 14CO332 & site & AV & LP & 4,266 & 3 & 0.38 & 0.32 & 0.85 & 0.05 & 0.11 \\
\hline 14CO382 & site & AV & LP & 12,922 & 5 & 0.74 & 0.40 & 0.77 & 0.08 & 0.15 \\
\hline 14CO385 & site & AV & LP & 255 & 2 & 0.20 & 0.45 & 0.33 & 0.00 & 0.67 \\
\hline 14CO501 & site & AV & LP & 37,008 & 7 & 0.87 & 0.23 & 0.87 & 0.04 & 0.09 \\
\hline 14RY401 & site & $\mathrm{P} / \mathrm{R}$ & LP & 224 & 11 & 1.88 & 0.63 & 0.05 & 0.62 & 0.33 \\
\hline 25FT22 & site & $\mathrm{P} / \mathrm{R}$ & LP & 7,287 & 6 & 0.56 & 0.27 & 0.01 & 0.10 & 0.90 \\
\hline 25LP8 & site & $\mathrm{P} / \mathrm{R}$ & LP & 274 & 5 & 0.72 & 0.15 & 0.89 & 0.08 & 0.03 \\
\hline 34CD257 & A & AV & W & 12,595 & 15 & 1.52 & 0.76 & 0.00 & 0.06 & 0.94 \\
\hline 34CD257 & PV & AV & LP & 1,636 & 10 & 1.26 & 0.75 & 0.01 & 0.04 & 0.95 \\
\hline 34CD258 & $A$ & $\mathrm{AV}$ & LP & 730 & 11 & 1.62 & 0.65 & 0.05 & 0.11 & 0.84 \\
\hline 48SW13156 & I & $\mathrm{P} / \mathrm{R}$ & $\mathrm{P}$ & 172 & 0 & & & 0.00 & 0.02 & 0.98 \\
\hline 48SW8842 & 5 & $\mathrm{P} / \mathrm{R}$ & $\mathrm{P}$ & 147 & 1 & 0.00 & 0.00 & 0.00 & 0.00 & 1.00 \\
\hline 48UT375 & Component 1 & $\mathrm{P} / \mathrm{R}$ & $\mathrm{P}$ & 926 & 1 & & & 0.00 & 0.00 & 1.00 \\
\hline 48UT375 & Component 2 & $\mathrm{P} / \mathrm{R}$ & $\mathrm{P}$ & 3,190 & 2 & 0.30 & 0.07 & 0.00 & 0.00 & 1.00 \\
\hline Agate Basin & Area 2-Folsom & $\mathrm{P} / \mathrm{R}$ & $\mathrm{P}$ & 1,910 & 10 & 1.19 & 0.51 & 0.54 & 0.45 & 0.01 \\
\hline Albert Bell & site & $\mathrm{P} / \mathrm{R}$ & LP & 1,022 & 5 & 0.58 & 0.35 & 0.80 & 0.08 & 0.12 \\
\hline Allen & $\begin{array}{l}\text { Occupation } \\
\text { Level } 1\end{array}$ & AV & $\mathrm{P}$ & 4,394 & 13 & 1.61 & 0.68 & 0.35 & 0.06 & 0.59 \\
\hline Allen & $\begin{array}{l}\text { Intermediate } \\
\text { Zone }\end{array}$ & AV & $\mathrm{P}$ & 1,387 & 13 & 1.93 & 0.82 & 0.13 & 0.15 & 0.72 \\
\hline Allen & $\begin{array}{l}\text { Occupation } \\
\text { Level } 2\end{array}$ & AV & $\mathrm{P}$ & 800 & 15 & 2.56 & 0.82 & 0.03 & 0.10 & 0.87 \\
\hline $\begin{array}{l}\text { Annie Site } \\
(25 \mathrm{DX} 30)\end{array}$ & site & $\mathrm{P} / \mathrm{R}$ & LP & 2,058 & 7 & 1.11 & 0.76 & 0.24 & 0.17 & 0.59 \\
\hline
\end{tabular}




\begin{tabular}{|c|c|c|c|c|c|c|c|c|c|c|}
\hline Arthur (13DK27) & $\begin{array}{l}\text { Middle } \\
\text { Woodland }\end{array}$ & $\mathrm{P} / \mathrm{R}$ & $\mathrm{W}$ & 976 & 13 & 1.76 & 0.44 & 0.18 & 0.01 & 0.81 \\
\hline Ash Hollow & Lens A & $\mathrm{P} / \mathrm{R}$ & LP & 21 & 3 & 0.78 & 0.64 & 0.10 & 0.00 & 0.90 \\
\hline Ash Hollow & Lens B & $\mathrm{P} / \mathrm{R}$ & LP & 47 & 7 & 1.60 & 0.68 & 0.21 & 0.21 & 0.57 \\
\hline Ash Hollow & Lens C & $\mathrm{P} / \mathrm{R}$ & LP & 163 & 9 & 1.58 & 0.59 & 0.11 & 0.17 & 0.72 \\
\hline Ash Hollow & Lens D & $\mathrm{P} / \mathrm{R}$ & $\mathrm{W}$ & 174 & 8 & 1.39 & 0.56 & 0.16 & 0.09 & 0.75 \\
\hline Ash Hollow & Lens E & $\mathrm{P} / \mathrm{R}$ & $\mathrm{W}$ & 16 & 4 & 1.25 & 0.69 & 0.00 & 0.19 & 0.81 \\
\hline Ash Hollow & Lens F & $\mathrm{P} / \mathrm{R}$ & A & 10 & 5 & 2.23 & 0.93 & 0.00 & 0.30 & 0.70 \\
\hline Aubrey & $\begin{array}{l}\text { Camp A and B; } \\
\text { Pond C/E1; Red } \\
\text { Sand S }\end{array}$ & AV & $\mathrm{P}$ & 1,523 & 7 & 0.86 & 0.63 & 0.34 & 0.01 & 0.64 \\
\hline Avoca (14JN332) & 1983 excavation & AV & LP & 157 & 6 & 1.20 & 0.79 & 0.39 & 0.35 & 0.25 \\
\hline Bagnell (32MO16) & Heart River & AV & LP & 5,460 & 5 & 0.47 & 0.15 & 0.83 & 0.05 & 0.12 \\
\hline Bagnell (32MO16) & Nailati Phase & $\mathrm{AV}$ & LP & 9,532 & 5 & 0.44 & 0.12 & 0.83 & 0.04 & 0.13 \\
\hline Big Black & site & AV & $\mathrm{P}$ & 836 & 0 & & & 0.41 & 0.02 & 0.57 \\
\hline Big Goose Creek & site & $\mathrm{F} / \mathrm{M}$ & LP & 209 & 14 & 2.73 & 0.85 & 0.00 & 0.24 & 0.76 \\
\hline Blood Run & site & AV & LP & 1,926 & 13 & 1.75 & 0.34 & 0.43 & 0.01 & 0.56 \\
\hline $\begin{array}{l}\text { Blue Point } \\
\text { (32SW5734) }\end{array}$ & Component 1 & $\mathrm{P} / \mathrm{R}$ & $\mathrm{P}$ & 120 & 1 & 0.00 & 0.00 & 0.10 & 0.25 & 0.65 \\
\hline $\begin{array}{l}\text { Blue Point } \\
\text { (32SW5734) }\end{array}$ & Component 2 & $\mathrm{P} / \mathrm{R}$ & $\mathrm{P}$ & 80 & 1 & 0.00 & 0.00 & 0.00 & 0.01 & 0.99 \\
\hline $\begin{array}{l}\text { Blue Point } \\
\text { (32SW5734) }\end{array}$ & Component 3 & $\mathrm{P} / \mathrm{R}$ & A & 299 & 1 & 0.00 & 0.00 & 0.06 & 0.01 & 0.93 \\
\hline $\begin{array}{l}\text { Blue Stone } \\
\text { (25HN45) }\end{array}$ & site & AV & LP & 127 & 4 & 0.62 & 0.05 & 0.98 & 0.01 & 0.02 \\
\hline Bottleneck Cave & II & $\mathrm{F} / \mathrm{M}$ & $\mathrm{P}$ & 13 & 1 & 0.00 & 0.00 & 0.00 & 0.92 & 0.08 \\
\hline
\end{tabular}




\begin{tabular}{|c|c|c|c|c|c|c|c|c|c|c|}
\hline Bottleneck Cave & III & $\mathrm{F} / \mathrm{M}$ & $\mathrm{P}$ & 41 & 3 & 0.71 & 0.54 & 0.00 & 0.80 & 0.20 \\
\hline Bottleneck Cave & IV & $\mathrm{F} / \mathrm{M}$ & A & 58 & 4 & 0.77 & 0.53 & 0.00 & 0.79 & 0.21 \\
\hline Bottleneck Cave & VI & $\mathrm{F} / \mathrm{M}$ & LP & 241 & 10 & 2.42 & 0.67 & 0.01 & 0.01 & 0.98 \\
\hline Bradford House II & $\mathrm{I}$ & $\mathrm{F} / \mathrm{M}$ & A & 32 & 6 & 1.70 & 0.75 & 0.28 & 0.19 & 0.53 \\
\hline Bradford House II & II & $\mathrm{F} / \mathrm{M}$ & $\mathrm{W}$ & 59 & 13 & 3.19 & 0.80 & 0.15 & 0.37 & 0.47 \\
\hline Brewster (13CK15) & $\begin{array}{l}1970 \\
\text { excavations }\end{array}$ & AV & LP & 7,768 & 8 & 0.86 & 0.68 & 0.23 & 0.05 & 0.73 \\
\hline $\begin{array}{l}\text { Broken Kettle West } \\
\text { (13PM25) }\end{array}$ & $\begin{array}{l}1968 \\
\text { excavations }\end{array}$ & AV & LP & 1,350 & 15 & 1.94 & 0.73 & 0.00 & 0.35 & 0.65 \\
\hline Buffalo Pasture & site & AV & LP & 2,918 & 14 & 1.67 & 0.37 & 0.64 & 0.07 & 0.28 \\
\hline Bunderbender & site & AV & LP & 201 & 10 & 1.76 & 0.74 & 0.00 & 0.36 & 0.64 \\
\hline $\begin{array}{l}\text { Cactus Flower } \\
(\text { EbOp-16) }\end{array}$ & Occupation IV & AV & A & 32 & 4 & 0.87 & 0.38 & 0.78 & 0.03 & 0.19 \\
\hline $\begin{array}{l}\text { Cactus Flower } \\
(\text { EbOp-16) }\end{array}$ & Occupation IX & AV & A & 73 & 4 & 0.70 & 0.11 & 0.95 & 0.03 & 0.03 \\
\hline $\begin{array}{l}\text { Cactus Flower } \\
(\text { EbOp-16) }\end{array}$ & Occupation VI & $\mathrm{AV}$ & A & 154 & 5 & 0.79 & 0.46 & 0.69 & 0.27 & 0.04 \\
\hline $\begin{array}{l}\text { Cactus Flower } \\
(\text { EbOp-16) }\end{array}$ & Occupation VII & $\mathrm{AV}$ & A & 53 & 4 & 0.76 & 0.15 & 0.92 & 0.00 & 0.08 \\
\hline $\begin{array}{l}\text { Cactus Flower } \\
(\text { EbOp-16) }\end{array}$ & Occupation VIII & $\mathrm{AV}$ & A & 660 & 7 & 0.92 & 0.10 & 0.95 & 0.02 & 0.03 \\
\hline $\begin{array}{l}\text { Canterbury } \\
\text { (5PE387) }\end{array}$ & site & $\mathrm{F} / \mathrm{M}$ & LP & 39 & 3 & 0.78 & 0.59 & 0.85 & 0.00 & 0.15 \\
\hline Cattleguard & site & $\mathrm{F} / \mathrm{M}$ & $\mathrm{P}$ & 3,517 & 2 & 0.12 & 0.00 & 1.00 & 0.00 & 0.00 \\
\hline
\end{tabular}




\begin{tabular}{|c|c|c|c|c|c|c|c|c|c|c|}
\hline $\begin{array}{l}\text { Chan-ya-ta } \\
\text { (13BV1) }\end{array}$ & House 6 & $\mathrm{P} / \mathrm{R}$ & LP & 1,249 & 11 & 1.42 & 0.66 & 0.31 & 0.04 & 0.64 \\
\hline Colby & site & $\mathrm{F} / \mathrm{M}$ & $\mathrm{P}$ & 463 & 1 & 0.00 & 0.00 & 1.00 & 0.00 & 0.00 \\
\hline Cow Killer & Area 751 & $\mathrm{P} / \mathrm{R}$ & LP & 2,615 & 12 & 1.47 & 0.29 & 0.04 & 0.77 & 0.19 \\
\hline $\begin{array}{l}\text { Cowan Site } \\
\text { (13WD88) }\end{array}$ & site & AV & LP & 11,233 & 14 & 1.81 & 0.62 & 0.02 & 0.04 & 0.94 \\
\hline Cramer (5PE484) & site & $\mathrm{F} / \mathrm{M}$ & LP & 48,859 & 11 & 1.19 & 0.25 & 0.97 & 0.00 & 0.02 \\
\hline $\begin{array}{l}\text { Crandall } \\
\text { (14RC420) }\end{array}$ & site & AV & LP & 16,125 & 17 & 1.66 & 0.34 & 0.78 & 0.00 & 0.22 \\
\hline Cross Ranch & Nailati Phase & AV & LP & 706 & 5 & 0.62 & 0.14 & 0.85 & 0.06 & 0.08 \\
\hline $\begin{array}{l}\text { Dahnke-Reinke } \\
\text { (32CS29) }\end{array}$ & $\begin{array}{l}\text { 1980s } \\
\text { excavation- } \\
\text { Early Woodland }\end{array}$ & AV & W & 6,484 & 6 & 1.09 & 0.57 & 0.52 & 0.01 & 0.47 \\
\hline $\begin{array}{l}\text { Dahnke-Reinke } \\
\text { (32CS29) }\end{array}$ & $\begin{array}{l}\text { 1980s } \\
\text { excavation- } \\
\text { LateWoodland }\end{array}$ & $\mathrm{AV}$ & $\mathrm{W}$ & 4,821 & 10 & 1.80 & 0.75 & 0.32 & 0.03 & 0.65 \\
\hline $\begin{array}{l}\text { Dahnke-Reinke } \\
\text { (32CS29) }\end{array}$ & $\begin{array}{l}\text { 1980s } \\
\text { excavation- } \\
\text { Middle } \\
\text { Woodland }\end{array}$ & $\mathrm{AV}$ & $\mathrm{W}$ & 11,845 & 6 & 0.98 & 0.55 & 0.58 & 0.00 & 0.42 \\
\hline DhPj-4 & Level 1 & $\mathrm{AV}$ & $\mathrm{W}$ & 45 & 1 & 0.00 & 0.00 & 1.00 & 0.00 & 0.00 \\
\hline DhPj-4 & Level 2 & AV & A & 18 & 1 & 0.00 & 0.00 & 1.00 & 0.00 & 0.00 \\
\hline Dixon (13WD8) & 1994 excavation & AV & LP & 3,949 & 11 & 1.45 & 0.54 & 0.15 & 0.10 & 0.75 \\
\hline Donovan & Level 1 & $\mathrm{P} / \mathrm{R}$ & LP & 1,966 & 5 & 0.53 & 0.25 & 0.85 & 0.00 & 0.15 \\
\hline Donovan & Level 9 & $\mathrm{P} / \mathrm{R}$ & LP & 1,935 & 6 & 0.66 & 0.21 & 0.88 & 0.00 & 0.11 \\
\hline Duncan (34WA2) & site & AV & LP & 42,595 & 6 & 0.56 & 0.19 & 0.27 & 0.57 & 0.17 \\
\hline
\end{tabular}




\begin{tabular}{|c|c|c|c|c|c|c|c|c|c|c|}
\hline Edward I (34BK2) & site & AV & LP & 2,336 & 8 & 0.91 & 0.52 & 0.46 & 0.04 & 0.50 \\
\hline $\begin{array}{l}\text { Glen Elder } \\
\text { (14ML1) }\end{array}$ & site & AV & LP & 18 & 5 & 1.44 & 0.67 & 0.06 & 0.11 & 0.83 \\
\hline Gowen 1 (FaNq25) & site & AV & A & 233 & 4 & 0.62 & 0.24 & 0.49 & 0.07 & 0.44 \\
\hline Gowen 2 (FaNq32) & site & AV & A & 385 & 5 & 0.73 & 0.13 & 0.56 & 0.03 & 0.41 \\
\hline Heerwald & site & AV & LP & 8,953 & 9 & 0.92 & 0.55 & 0.57 & 0.12 & 0.31 \\
\hline Helen Lookingbill & Layer 2/4 & $\mathrm{F} / \mathrm{M}$ & $\mathrm{P}$ & 25 & 2 & 0.31 & 0.23 & 0.12 & 0.84 & 0.04 \\
\hline Helen Lookingbill & Layer 7/9 & $\mathrm{F} / \mathrm{M}$ & $\mathrm{P}$ & 531 & 3 & 0.32 & 0.30 & 0.01 & 0.99 & 0.00 \\
\hline Hell Gap & $\begin{array}{l}\text { Locality II- } \\
\text { Alberta }\end{array}$ & $\mathrm{F} / \mathrm{M}$ & $\mathrm{P}$ & 1,316 & 2 & 0.14 & 0.00 & 0.99 & 0.01 & 0.00 \\
\hline Hell Gap & $\begin{array}{l}\text { Locality I- } \\
\text { Unknown }\end{array}$ & $\mathrm{F} / \mathrm{M}$ & $\mathrm{P}$ & 1,388 & 3 & 0.34 & 0.01 & 0.99 & 0.00 & 0.01 \\
\hline Hill & site & $\mathrm{AV}$ & A & 164 & 5 & 0.89 & 0.56 & 0.75 & 0.04 & 0.21 \\
\hline Horner & I & $\mathrm{F} / \mathrm{M}$ & $\mathrm{P}$ & 2,154 & 3 & 0.26 & 0.01 & 0.99 & 0.00 & 0.00 \\
\hline $\begin{array}{l}\text { Horsetheif } \\
(14 \mathrm{HO} 308)\end{array}$ & site & $\mathrm{P} / \mathrm{R}$ & LP & 3,330 & 4 & 0.46 & 0.20 & 0.94 & 0.02 & 0.04 \\
\hline Hulme & site & AV & LP & 1,476 & 6 & 0.69 & 0.64 & 0.02 & 0.48 & 0.51 \\
\hline Indian Creek & site & $\mathrm{AV}$ & LP & 356 & 7 & 1.04 & 0.51 & 0.58 & 0.26 & 0.16 \\
\hline Jackson & site & $\mathrm{P} / \mathrm{R}$ & LP & 4,464 & 7 & 0.72 & 0.02 & 0.96 & 0.00 & 0.04 \\
\hline $\begin{array}{l}\text { Jake White Bull } \\
\text { (39CO6) }\end{array}$ & site & AV & LP & 330 & 4 & 0.55 & 0.15 & 0.65 & 0.02 & 0.33 \\
\hline $\begin{array}{l}\text { Juan Baca } \\
\text { (5LA1085) }\end{array}$ & site & $\mathrm{F} / \mathrm{M}$ & LP & 48 & 5 & 1.18 & 0.69 & 0.38 & 0.02 & 0.60 \\
\hline Jurgens & Area 2 & AV & $\mathrm{P}$ & 101 & 4 & 0.65 & 0.08 & 0.93 & 0.03 & 0.04 \\
\hline Kelso (25HO23) & site & AV & $\mathrm{W}$ & 92 & 9 & 1.88 & 0.81 & 0.10 & 0.20 & 0.71 \\
\hline Lake Theo & Folsom & $\mathrm{P} / \mathrm{R}$ & $\mathrm{P}$ & 6,919 & 1 & 0.00 & 0.00 & 1.00 & 0.00 & 0.00 \\
\hline
\end{tabular}




\begin{tabular}{|c|c|c|c|c|c|c|c|c|c|c|}
\hline Landergin Mesa & site & AV & LP & 1,854 & 8 & 0.97 & 0.54 & 0.41 & 0.22 & 0.37 \\
\hline Leavitt & site & AV & LP & 106 & 9 & 1.80 & 0.52 & 0.55 & 0.10 & 0.35 \\
\hline Lewisville & $\begin{array}{l}(1949-1957 \text { and } \\
1978-1980)\end{array}$ & AV & $\mathrm{P}$ & 466 & 9 & 1.56 & 0.71 & 0.05 & 0.04 & 0.92 \\
\hline $\begin{array}{l}\text { Lightning Spring } \\
(39 H N 204)\end{array}$ & Stratum 1 & $\mathrm{~F} / \mathrm{M}$ & LP & 31 & 4 & 1.04 & 0.53 & 0.68 & 0.16 & 0.16 \\
\hline $\begin{array}{l}\text { Lightning Spring } \\
(39 H N 204)\end{array}$ & Stratum 10 & $\mathrm{~F} / \mathrm{M}$ & A & 39 & 2 & 0.32 & 0.09 & 0.08 & 0.77 & 0.15 \\
\hline $\begin{array}{l}\text { Lightning Spring } \\
(39 H N 204)\end{array}$ & Stratum 11 & $\mathrm{~F} / \mathrm{M}$ & A & 114 & 4 & 0.68 & 0.35 & 0.20 & 0.78 & 0.02 \\
\hline $\begin{array}{l}\text { Lightning Spring } \\
(39 H N 204)\end{array}$ & Stratum 12 & $\mathrm{~F} / \mathrm{M}$ & A & 24 & 2 & 0.46 & 0.39 & 0.13 & 0.88 & 0.00 \\
\hline $\begin{array}{l}\text { Lightning Spring } \\
(39 H N 204)\end{array}$ & Stratum 14 & $\mathrm{~F} / \mathrm{M}$ & A & 11 & 2 & & & 0.27 & 0.73 & 0.00 \\
\hline $\begin{array}{l}\text { Lightning Spring } \\
\text { (39HN204) }\end{array}$ & Stratum 2 & $\mathrm{~F} / \mathrm{M}$ & A & 16 & 2 & 0.48 & 0.43 & 0.88 & 0.13 & 0.00 \\
\hline $\begin{array}{l}\text { Lightning Spring } \\
(39 H N 204)\end{array}$ & Stratum 3 & $\mathrm{~F} / \mathrm{M}$ & A & 27 & 1 & & & 0.96 & 0.00 & 0.04 \\
\hline $\begin{array}{l}\text { Lightning Spring } \\
(39 H N 204)\end{array}$ & Stratum 8 & $\mathrm{~F} / \mathrm{M}$ & A & 62 & 3 & 0.63 & 0.37 & 0.06 & 0.90 & 0.03 \\
\hline $\begin{array}{l}\text { Lightning Spring } \\
(39 H N 204)\end{array}$ & Stratum 9 & $\mathrm{~F} / \mathrm{M}$ & A & 12 & 2 & & & 0.83 & 0.17 & 0.00 \\
\hline Lime Creek & Zone I & AV & $\mathrm{P}$ & 519 & 5 & 0.72 & 0.63 & 0.28 & 0.15 & 0.57 \\
\hline Lindenmeier & Folsom & $\mathrm{P} / \mathrm{R}$ & $\mathrm{P}$ & 593 & 5 & 0.63 & 0.18 & 0.88 & 0.01 & 0.11 \\
\hline Linger & SI 1977-1979 & $\mathrm{F} / \mathrm{M}$ & $\mathrm{P}$ & 462 & 1 & 0.00 & 0.00 & 1.00 & 0.00 & 0.00 \\
\hline Logan Creek & Zone A & $\mathrm{AV}$ & A & 200 & 3 & 0.38 & 0.04 & 0.97 & 0.01 & 0.03 \\
\hline Logan Creek & Zone B & AV & A & 938 & 10 & 1.32 & 0.05 & 0.96 & 0.01 & 0.03 \\
\hline Logan Creek & Zone C & AV & A & 236 & 9 & 1.47 & 0.59 & 0.58 & 0.02 & 0.40 \\
\hline Logan Creek & Zone D & $\mathrm{AV}$ & A & 271 & 7 & 1.07 & 0.16 & 0.90 & 0.00 & 0.09 \\
\hline Logan Creek & Zone F & AV & A & 61 & 2 & 0.24 & 0.10 & 0.93 & 0.07 & 0.00 \\
\hline
\end{tabular}




\begin{tabular}{|c|c|c|c|c|c|c|c|c|c|c|}
\hline $\begin{array}{l}\text { Lundeen } \\
\text { (14MD306) }\end{array}$ & site & AV & LP & 5,988 & 11 & 1.16 & 0.65 & 0.11 & 0.08 & 0.81 \\
\hline MAD (13CF101) & Boyer & $\mathrm{AV}$ & $\mathrm{W}$ & 2,726 & 14 & 2.19 & 0.71 & 0.23 & 0.49 & 0.28 \\
\hline MAD (13CF101) & Valley & AV & $\mathrm{W}$ & 447 & 9 & 1.81 & 0.75 & 0.04 & 0.51 & 0.45 \\
\hline MAD (13CF102) & Valley & AV & $\mathrm{W}$ & 119 & 6 & 2.01 & 0.76 & 0.06 & 0.15 & 0.79 \\
\hline MAD (13CF102) & Boyer & AV & W & 449 & 8 & 1.41 & 0.41 & 0.41 & 0.39 & 0.20 \\
\hline MAD (13CF102) & Loseke & AV & $\mathrm{W}$ & 4,410 & 12 & 1.72 & 0.60 & 0.51 & 0.28 & 0.21 \\
\hline Mangus & III & $\mathrm{F} / \mathrm{M}$ & LP & 117 & 2 & 0.23 & 0.18 & 0.07 & 0.64 & 0.29 \\
\hline Mangus & Red silt & $\mathrm{F} / \mathrm{M}$ & LP & 10 & 2 & 0.48 & 0.25 & 0.70 & 0.10 & 0.20 \\
\hline McIntoch & site & $\mathrm{P} / \mathrm{R}$ & LP & 3,787 & 11 & 1.22 & 0.43 & 0.16 & 0.01 & 0.83 \\
\hline $\begin{array}{l}\text { Medicine Lodge } \\
\text { Creek }\end{array}$ & 23 ft-deep deer & $\mathrm{F} / \mathrm{M}$ & $\mathrm{P}$ & 65 & 5 & 1.16 & 0.44 & 0.03 & 0.35 & 0.62 \\
\hline $\begin{array}{l}\text { Medicine Lodge } \\
\text { Creek }\end{array}$ & Cody & $\mathrm{F} / \mathrm{M}$ & $\mathrm{P}$ & 28 & 4 & 0.99 & 0.42 & 0.07 & 0.14 & 0.79 \\
\hline $\begin{array}{l}\text { Medicine Lodge } \\
\text { Creek }\end{array}$ & $\begin{array}{l}\text { Foothill- } \\
\text { Mountain-North } \\
\text { Paleoindian }\end{array}$ & $\mathrm{F} / \mathrm{M}$ & $\mathrm{P}$ & 14 & 6 & 2.01 & 0.85 & 0.29 & 0.36 & 0.36 \\
\hline $\begin{array}{l}\text { Medicine Lodge } \\
\text { Creek }\end{array}$ & $\begin{array}{l}\text { Lovell } \\
\text { Constricted-fir } \\
\text { pit level }\end{array}$ & $\mathrm{F} / \mathrm{M}$ & $\mathrm{P}$ & 95 & 9 & 1.86 & 0.79 & 0.00 & 0.28 & 0.72 \\
\hline $\begin{array}{l}\text { Medicine Lodge } \\
\text { Creek }\end{array}$ & Pryor stemmed & $\mathrm{F} / \mathrm{M}$ & $\mathrm{P}$ & 52 & 8 & 1.92 & 0.73 & 0.02 & 0.48 & 0.50 \\
\hline $\begin{array}{l}\text { Mondrian Tree } \\
\text { (32MZ58) }\end{array}$ & $\begin{array}{l}1981 \\
\text { excavation- } \\
\text { Zone } 2\end{array}$ & AV & A & 67 & 5 & 0.99 & 0.34 & 0.79 & 0.15 & 0.06 \\
\hline $\begin{array}{l}\text { Mondrian Tree } \\
\text { (32MZ58) }\end{array}$ & $\begin{array}{l}1981 \\
\text { excavation- } \\
\text { Zone } 3\end{array}$ & $\mathrm{AV}$ & A & 77 & 4 & 0.72 & 0.12 & 0.94 & 0.01 & 0.05 \\
\hline
\end{tabular}




\begin{tabular}{|c|c|c|c|c|c|c|c|c|c|c|}
\hline $\begin{array}{l}\text { Mondrian Tree } \\
\text { (32MZ58) }\end{array}$ & $\begin{array}{l}1981 \\
\text { excavation- } \\
\text { Zone } 4\end{array}$ & AV & A & 131 & 6 & 1.07 & 0.72 & 0.38 & 0.54 & 0.08 \\
\hline $\begin{array}{l}\text { Mondrian Tree } \\
\text { (32MZ58) }\end{array}$ & $\begin{array}{l}1981 \\
\text { excavation- } \\
\text { Zone } 5\end{array}$ & AV & A & 23 & 3 & 0.67 & 0.19 & 0.87 & 0.04 & 0.09 \\
\hline $\begin{array}{l}\text { Mondrian Tree } \\
\text { (32MZ58) }\end{array}$ & $\begin{array}{l}1981 \\
\text { excavation- } \\
\text { Zone } 6\end{array}$ & AV & A & 36 & 2 & 0.32 & 0.09 & 0.81 & 0.03 & 0.17 \\
\hline $\begin{array}{l}\text { Mondrian Tree } \\
\text { (32MZ58) }\end{array}$ & $\begin{array}{l}1981 \\
\text { excavation- } \\
\text { Zone } 7\end{array}$ & AV & A & 30 & 4 & 0.97 & 0.69 & 0.50 & 0.30 & 0.20 \\
\hline Mummy Cave & Layer 1 & $\mathrm{~F} / \mathrm{M}$ & $\mathrm{P}$ & 35 & 4 & 1.30 & 0.71 & 0.00 & 0.14 & 0.86 \\
\hline Mummy Cave & Layer 4 & $\mathrm{~F} / \mathrm{M}$ & $\mathrm{P}$ & 33 & 6 & 1.70 & 0.87 & 0.00 & 0.52 & 0.48 \\
\hline Mummy Cave & Layer 6 & $\mathrm{~F} / \mathrm{M}$ & $\mathrm{P}$ & 46 & 4 & 0.91 & 0.74 & 0.00 & 0.38 & 0.63 \\
\hline Mummy Cave & Layer 8 & $\mathrm{~F} / \mathrm{M}$ & $\mathrm{P}$ & 85 & 4 & 0.76 & 0.31 & 0.00 & 0.98 & 0.02 \\
\hline Mummy Cave & Layer 9 & $\mathrm{~F} / \mathrm{M}$ & $\mathrm{P}$ & 108 & 1 & 0.00 & 0.00 & 0.00 & 0.99 & 0.01 \\
\hline Mummy Cave & Layer 10 & $\mathrm{~F} / \mathrm{M}$ & $\mathrm{P}$ & 145 & 4 & 0.65 & 0.09 & 0.00 & 0.94 & 0.06 \\
\hline Mummy Cave & Layer 11 & $\mathrm{~F} / \mathrm{M}$ & $\mathrm{P}$ & 95 & 2 & 0.23 & 0.05 & 0.00 & 1.00 & 0.00 \\
\hline Mummy Cave & Layer 12 & $\mathrm{~F} / \mathrm{M}$ & $\mathrm{P}$ & 179 & 5 & 0.88 & 0.25 & 0.00 & 0.91 & 0.09 \\
\hline Mummy Cave & Layer 14 & $\mathrm{~F} / \mathrm{M}$ & $\mathrm{P}$ & 17 & 3 & 0.76 & 0.47 & 0.00 & 0.76 & 0.24 \\
\hline Munsell (5PE797) & site & $\mathrm{F} / \mathrm{M}$ & LP & 19 & 2 & 0.51 & 0.29 & 0.89 & 0.05 & 0.05 \\
\hline Myers-Hinderman & Unit 1 & $\mathrm{~F} / \mathrm{M}$ & $\mathrm{P}$ & 40 & 7 & 1.63 & 0.78 & 0.35 & 0.58 & 0.08 \\
\hline Myers-Hinderman & Unit 3 & $\mathrm{~F} / \mathrm{M}$ & A & 142 & 6 & 1.01 & 0.67 & 0.35 & 0.65 & 0.01 \\
\hline Myers-Hinderman & Unit 4 & $\mathrm{~F} / \mathrm{M}$ & A & 179 & 10 & 1.73 & 0.77 & 0.28 & 0.68 & 0.04 \\
\hline Myers-Hinderman & Unit 5 & $\mathrm{~F} / \mathrm{M}$ & A & 108 & 7 & 1.28 & 0.78 & 0.31 & 0.67 & 0.03 \\
\hline
\end{tabular}




\begin{tabular}{|c|c|c|c|c|c|c|c|c|c|c|}
\hline Myers-Hinderman & Unit 6 & $\mathrm{~F} / \mathrm{M}$ & A & 71 & 6 & 1.18 & 0.65 & 0.54 & 0.41 & 0.06 \\
\hline Myers-Hinderman & Unit 7 & $\mathrm{~F} / \mathrm{M}$ & $\mathrm{W}$ & 39 & 7 & 1.64 & 0.62 & 0.59 & 0.36 & 0.05 \\
\hline Myers-Hinderman & Unit 8 & $\mathrm{~F} / \mathrm{M}$ & LP & 46 & 5 & 1.04 & 0.65 & 0.48 & 0.52 & 0.00 \\
\hline Naze (32SN246) & $\begin{array}{l}\text { Zone 1: plains } \\
\text { village }\end{array}$ & AV & LP & 123 & 3 & 0.78 & 0.60 & 0.89 & 0.01 & 0.11 \\
\hline Naze (32SN246) & $\begin{array}{l}\text { Zone 2: Middle } \\
\text { Woodland }\end{array}$ & AV & W & 381 & 3 & 0.47 & 0.11 & 0.58 & 0.24 & 0.18 \\
\hline Naze (32SN246) & $\begin{array}{l}\text { Zone 3: Early } \\
\text { Woodland }\end{array}$ & AV & W & 71 & 4 & 0.82 & 0.64 & 0.58 & 0.27 & 0.15 \\
\hline $\begin{array}{l}\text { Odessa Yates } \\
\text { (34BV100) }\end{array}$ & $\begin{array}{l}\text { 1998-2000 } \\
\text { excavations }\end{array}$ & AV & LP & 22,388 & 8 & 0.86 & 0.50 & 0.88 & 0.04 & 0.08 \\
\hline Oliphant (14LT316) & 1973 excavation & AV & LP & 440 & 9 & 1.57 & 0.50 & 0.04 & 0.69 & 0.27 \\
\hline OV Clary & Middle & $\mathrm{P} / \mathrm{R}$ & $\mathrm{P}$ & 1,000 & 1 & 0.00 & 0.00 & 1.00 & 0.00 & 0.00 \\
\hline $\begin{array}{l}\text { Oxbow Dam } \\
\text { (DhMN-1) }\end{array}$ & $\begin{array}{l}\text { Cultural Level } \\
4-1995 / 96\end{array}$ & AV & A & 648 & 1 & 0.00 & 0.00 & 1.00 & 0.00 & 0.00 \\
\hline $\begin{array}{l}\text { Oxbow Dam } \\
\text { (DhMN-1) }\end{array}$ & $\begin{array}{l}\text { Cultural Level } \\
\text { 5-1995/96 }\end{array}$ & AV & A & 69 & 4 & 0.71 & 0.09 & 0.93 & 0.00 & 0.07 \\
\hline $\begin{array}{l}\text { Oxbow Dam } \\
\text { (DhMN-1) }\end{array}$ & $\begin{array}{l}\text { Cultural Level } \\
\text { 6-1995/96 }\end{array}$ & AV & A & 251 & 7 & 1.21 & 0.35 & 0.45 & 0.00 & 0.55 \\
\hline Phil (14JW48) & site & AV & LP & 92 & 9 & 1.86 & 0.86 & 0.16 & 0.15 & 0.68 \\
\hline Phipps (13CK21) & $\begin{array}{l}1994 \\
\text { excavations }\end{array}$ & $\mathrm{AV}$ & LP & 583 & 4 & 0.51 & 0.46 & 0.44 & 0.15 & 0.41 \\
\hline Phipps (13CK21) & $\begin{array}{l}\text { pre-1970s } \\
\text { excavations }\end{array}$ & AV & LP & 4,829 & 8 & 0.87 & 0.66 & 0.34 & 0.14 & 0.52 \\
\hline Rainbow (13PM91) & Horizon A & AV & $\mathrm{W}$ & 2,067 & 15 & 2.36 & 0.78 & 0.40 & 0.11 & 0.49 \\
\hline Rainbow (13PM91) & Horizon B & AV & $\mathrm{W}$ & 850 & 12 & 2.58 & 0.75 & 0.03 & 0.02 & 0.96 \\
\hline
\end{tabular}




\begin{tabular}{|c|c|c|c|c|c|c|c|c|c|c|}
\hline Rainbow (13PM91) & Horizon C & AV & $\mathrm{W}$ & 4,562 & 14 & 1.93 & 0.85 & 0.02 & 0.11 & 0.87 \\
\hline Rainbow (13PM91) & Horizon D & AV & $\mathrm{W}$ & 1,151 & 10 & 1.36 & 0.19 & 0.12 & 0.05 & 0.83 \\
\hline SCHMIDT & Site & AV & LP & 3,334 & 13 & 1.54 & 0.75 & 0.15 & 0.07 & 0.77 \\
\hline Sharp's (13ML42) & Site & AV & $\mathrm{W}$ & 388 & 9 & 1.47 & 0.37 & 0.03 & 0.73 & 0.24 \\
\hline $\begin{array}{l}\text { Sibbald Creek } \\
(\text { EgPr-2) }\end{array}$ & Levels $0-10 \mathrm{~cm}$ & $\mathrm{~F} / \mathrm{M}$ & LP & 95 & 6 & 1.10 & 0.34 & 0.81 & 0.13 & 0.06 \\
\hline $\begin{array}{l}\text { Snake Blakeslee } \\
\text { (5LA1247) }\end{array}$ & site & $\mathrm{F} / \mathrm{M}$ & LP & 983 & 8 & 1.21 & 0.70 & 0.64 & 0.04 & 0.32 \\
\hline Sorenson & IV & $\mathrm{F} / \mathrm{M}$ & A & 16 & 1 & 0.00 & 0.00 & 0.00 & 1.00 & 0.00 \\
\hline Sorenson & VI & $\mathrm{F} / \mathrm{M}$ & LP & 23 & 3 & 0.64 & 0.37 & 0.17 & 0.78 & 0.04 \\
\hline $\begin{array}{l}\text { South Cannonball } \\
\text { River (32SI19) }\end{array}$ & site & AV & LP & 8,673 & 6 & 0.56 & 0.22 & 0.81 & 0.02 & 0.16 \\
\hline Stigenwalt & Archaic & AV & A & 344 & 8 & 1.83 & 0.74 & 0.00 & 0.06 & 0.94 \\
\hline Sun River & Level IV & $\mathrm{F} / \mathrm{M}$ & A & 761 & 6 & 0.83 & 0.09 & 0.94 & 0.03 & 0.03 \\
\hline Sun River & Level V & $\mathrm{F} / \mathrm{M}$ & A & 626 & 5 & 0.68 & 0.52 & 0.65 & 0.33 & 0.02 \\
\hline Sun River & Level VI & $\mathrm{F} / \mathrm{M}$ & A & 1,391 & 6 & 0.84 & 0.32 & 0.03 & 0.82 & 0.14 \\
\hline $\begin{array}{l}\text { Theodore Davis } \\
\text { (25CC17) }\end{array}$ & site & AV & LP & 118 & 6 & 1.37 & 0.59 & 0.59 & 0.26 & 0.14 \\
\hline Travis I (39CO213) & site & AV & LP & 711 & 4 & 0.46 & 0.52 & 0.49 & 0.00 & 0.51 \\
\hline Trowbridge & site & $\mathrm{P} / \mathrm{R}$ & W & 5,078 & 12 & 1.66 & 0.52 & 0.00 & 0.52 & 0.48 \\
\hline Two Sisters & site & AV & LP & 11,531 & 8 & 0.93 & 0.59 & 0.62 & 0.22 & 0.16 \\
\hline $\begin{array}{l}\text { Upper Sanger } \\
\text { (32OL12) }\end{array}$ & Heart River & AV & LP & 497 & 5 & 0.65 & 0.09 & 0.89 & 0.04 & 0.07 \\
\hline Vera & site & $\mathrm{P} / \mathrm{R}$ & LP & 1,676 & 9 & 1.09 & 0.09 & 0.90 & 0.00 & 0.10 \\
\hline Vermilion Lakes & Component 7 & $\mathrm{~F} / \mathrm{M}$ & $\mathrm{P}$ & 50 & 2 & 0.26 & 0.08 & 0.00 & 0.96 & 0.04 \\
\hline Vermilion Lakes & Component 8 & $\mathrm{~F} / \mathrm{M}$ & $\mathrm{P}$ & 109 & 3 & 0.43 & 0.36 & 0.02 & 0.77 & 0.21 \\
\hline
\end{tabular}




\begin{tabular}{|c|c|c|c|c|c|c|c|c|c|c|}
\hline Vermilion Lakes & Component 9a & $\mathrm{F} / \mathrm{M}$ & $\mathrm{P}$ & 17 & 4 & 1.11 & 0.62 & 0.00 & 0.82 & 0.18 \\
\hline Vermilion Lakes & Component 9b & $\mathrm{F} / \mathrm{M}$ & $\mathrm{P}$ & 11 & 1 & 0.00 & 0.00 & 0.00 & 1.00 & 0.00 \\
\hline $\begin{array}{l}\text { Walker Gilmore } \\
\text { (25CC28) }\end{array}$ & $\begin{array}{l}1968 \\
\text { excavation- } \\
\text { Level 1 }\end{array}$ & AV & A & 50 & 6 & 1.30 & 0.43 & 0.00 & 0.02 & 0.98 \\
\hline $\begin{array}{l}\text { Walker Gilmore } \\
\text { (25CC28) }\end{array}$ & $\begin{array}{l}1968 \\
\text { excavation- } \\
\text { Level } 2\end{array}$ & $\mathrm{AV}$ & $\mathrm{W}$ & 78 & 4 & 0.70 & 0.60 & 0.00 & 0.10 & 0.90 \\
\hline $\begin{array}{l}\text { Walker Gilmore } \\
\text { (25CC28) }\end{array}$ & $\begin{array}{l}1968 \\
\text { excavation- } \\
\text { Level } 3\end{array}$ & $\mathrm{AV}$ & W & 91 & 6 & 1.13 & 0.58 & 0.04 & 0.20 & 0.76 \\
\hline $\begin{array}{l}\text { Walker Gilmore } \\
\text { (25CC28) }\end{array}$ & $\begin{array}{l}1968 \\
\text { excavation- } \\
\text { Level } 4\end{array}$ & $\mathrm{AV}$ & $\mathrm{W}$ & 110 & 5 & 0.85 & 0.64 & 0.01 & 0.07 & 0.92 \\
\hline $\begin{array}{l}\text { Walker Gilmore } \\
\text { (25CC28) }\end{array}$ & $\begin{array}{l}1968 \\
\text { excavation- } \\
\text { Level } 5\end{array}$ & $\mathrm{AV}$ & W & 74 & 5 & 0.94 & 0.48 & 0.03 & 0.22 & 0.76 \\
\hline Waugh & site & $\mathrm{P} / \mathrm{R}$ & $\mathrm{P}$ & 1,403 & 1 & 0.00 & 0.00 & 1.00 & 0.00 & 0.00 \\
\hline $\begin{array}{l}\text { White Buffalo Robe } \\
\text { (32ME7) }\end{array}$ & Heart River & $\mathrm{AV}$ & LP & 2,147 & 4 & 0.40 & 0.06 & 0.84 & 0.02 & 0.14 \\
\hline $\begin{array}{l}\text { White Buffalo Robe } \\
\text { (32ME7) }\end{array}$ & Nailati Phase & $\mathrm{AV}$ & LP & 1,469 & 3 & 0.29 & 0.13 & 0.60 & 0.04 & 0.36 \\
\hline Wilson Leonard & $\begin{array}{l}\text { Early } \\
\text { Paleoindian } \\
\text { Bonebed: Units } \\
\text { Isi, Isi/Icl, } \\
\text { Igl/Isi, Isi/Isi-c, } \\
\text { Isi/Icl/Isi-c }\end{array}$ & AV & $\mathrm{P}$ & 311 & 3 & 0.47 & 0.57 & 0.12 & 0.74 & 0.14 \\
\hline
\end{tabular}




\begin{tabular}{|c|c|c|c|c|c|c|c|c|c|c|}
\hline Wilson Leonard & $\begin{array}{l}\text { Unit II: } \\
\text { (Golindria- } \\
\text { Barber, St } \\
\text { Mary's, } \\
\text { Angostura) }\end{array}$ & $\mathrm{AV}$ & $\mathrm{P}$ & 606 & 6 & 0.96 & 0.66 & 0.01 & 0.66 & 0.33 \\
\hline Wilson Leonard & $\begin{array}{l}\text { Upper Unit I: } \\
\text { (Wilson) }\end{array}$ & AV & $\mathrm{P}$ & 430 & 6 & 1.08 & 0.65 & 0.00 & 0.75 & 0.24 \\
\hline Witt & Site & AV & LP & 1,188 & 10 & 1.31 & 0.81 & 0.01 & 0.15 & 0.85 \\
\hline Yarmony (5EA799) & Ceramic locus & $\mathrm{F} / \mathrm{M}$ & LP & 68 & 1 & 0.00 & 0.00 & 0.03 & 0.43 & 0.53 \\
\hline Yarmony (5EA799) & $\begin{array}{l}\text { Pithouse locus- } \\
\text { House } 1 \& 2\end{array}$ & $\mathrm{~F} / \mathrm{M}$ & A & 2,006 & 6 & 1.09 & 0.50 & 0.03 & 0.50 & 0.47 \\
\hline Yarmony (5EA799) & $\begin{array}{l}\text { Pithouse locus- } \\
\text { Midden F14 }\end{array}$ & $\mathrm{F} / \mathrm{M}$ & A & 45 & 2 & & & 0.00 & 0.83 & 0.17 \\
\hline
\end{tabular}

